NASA Contractor Report 185161

LSPI-901

\title{
A Superconducting Quenchgun for Delivering Lunar Derived Oxygen to Lunar Orbit
}

Nathan Nottke and Curt Bilby

Large Scale Programs Institute

Austin, Texas

April 1990

Prepared for

Lewis Research Center

Under Grant NAG3-928

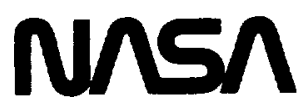

National Aeronautics and

Space Administration

(NASA-CR-185161) A SUPFRCONUUCTING

UUENCHGUN FOR DFLIVERING LUNAR DERIVED

UXVIEN TO LUNAR OOBIT Final Report

scale programs (nst.)

(Large

CSCL 220

220 Unclas

$63 / 20 \quad 0275662$ 
- 
ERRATA

NASA Contractor Report 185161

\title{
A SUPERCONDICTIONG QUENCHGUN FOR DELIVERING LUNAR DERIVED OXYGEN TO LUNAR ORBIT
}

\author{
Nathan Nottke and Curt Bilby
}

Cover and Report Documentation Page: The NASA Contractor Report number should be changed from 185163 to 185161 . 



\section{TABLE OF CONTENTS}

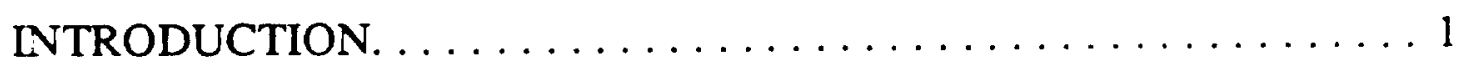

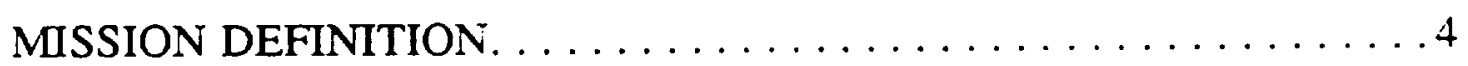

QUENCHGUN DESIGN AND SIZING $\ldots \ldots \ldots \ldots \ldots \ldots \ldots \ldots$

SLPPORT SYSTEM COMPONENTS AND SIZING $\ldots \ldots \ldots \ldots \ldots 14$

NTEGRATED LAUNCHER AND SUPPORT SYSTEM MODEL. . . . . 21

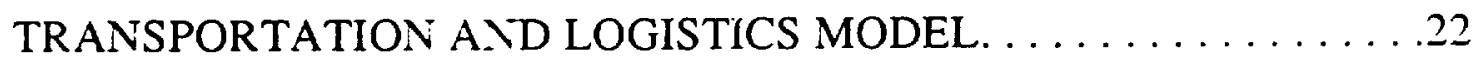

LOCAL EVALUATION WITH LUNAR EVOLUTION CASE STUDY. . .25

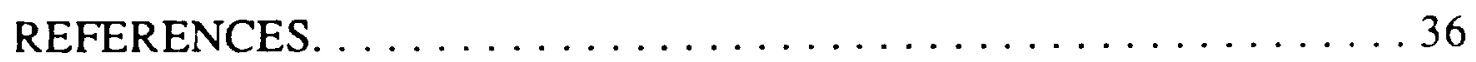

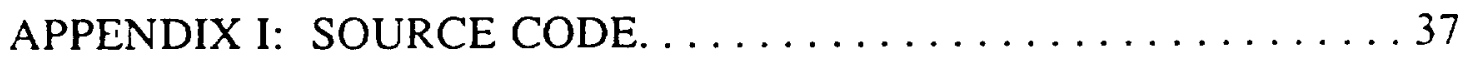




\section{Executive Summary}

The present long range goals in the exploration of space include the establishment of a permanently manned lunar base followed by manned exploration of Mars. The realization of the first goal alone will require a significant increase in the materials and supplies delivered from Earth to orbit. Some of these supplies, such as fuel, will be utilized in the delivery of infrastructure to the lunar surface. From a management perspective, these consumables can be considered operating overhead. One way to reduce and avoid the cost of delivering fuel to space is to use what is already available in the lunar environment. Liquid oxygen, which can be derived from lunar soil, accounts for over 80 percent of the fuel mass for advanced chemical propulsion systems.

The primary mission under consideration is the non-chemical delivery of lunar derived liquid oxygen to lunar orbit for use as oxidizer by a cislunar transportation system. Chemical transport reduces the efficiency of producing lunar oxygen by using the product during delivery. The use of an electromagnetic launcher would avoid this waste and might produce long term savings for a lunar evolutionary policy with an emphasis on aggressive in-situ materials utilization. The purpose of this study is to define this electromagnetic launcher, its necessary support systems, then formulate and code parametric scaling algorithms for these systems as a function of liquid oxygen payload and hours between launches. It is also desired to examine the impact an electromagnetic launcher would have to the present NASA Office of Exploration Lunar Evolution Case Study.

By using commercially available niobium titanium alloy superconductors, the Massachusetts Institute of Technology (MIT) mass driver group found that the entire launch energy can be stored directly in the drive coils, eliminating the need for external energy 
storage devices. External energy storage devices, such as capacitors, tend to be larger and more massive than practicality would allow for lunar surface delivery and operation. With internal storage of the launch energy in a resistance free device, no losses are incurred during charging or launch. This design, termed a quenchgun, is the most efficient launcher theoretically possible.

Two important parameters that impact the size and support requirements of the launcher are the payload mass and the firing rate. Clearly, these two quantities will deviate according to the lunar evolution scenario that is considered. For this reason, it was desired to devise a method of scaling the size of the launcher and associated support systems based on these parameters. Using these two parameters as the model drivers, scaling relations were developed and coded in FORTRAN. The program requires the payload mass, in the range of one to twenty metric tons, and the launch frequency in hours to calculate a detailed mass inventory of launcher and support components. Like many complex devices, the quenchgun can be reduced into discrete subsystems. The systems that comprise the quenchgun were divided into two groups: those integral to the launcher and those support systems required to make the launcher autonomous. To evaluate the impact of quenchgun emplacement, an optimizing cislunar transportation model was developed. It's purpose is to calculate the minimum flight requirement to deliver a given cargo and crew to the lunar surface.

The impact of a lunar quenchgun on the Lunar Evolution Case Study was performed by considering three lunar oxygen production scenarios: low production ( $96 \mathrm{MT} / \mathrm{yr}$ ), medium production (300 $\mathrm{MT} / \mathrm{yr})$, and high production (600 MT/yr). The high production scenario was most favorable to quenchgun emplacement. Even in this case, a savings in mass delivered to low earth orbit was not evident until seven years after launcher operations begin. The launcher can have a maximum lifetime of ten years after this 
breakeven point before major structural failure or comprehensive overhaul. With a substantial initial investment over two years for launcher delivery, plus the delivery of additional oxygen processing equipment, this scenario including the lunar quenchgun is nominal at best. 


\section{INTRODUCTION}

In a speech delivered on the 20th anniversary of the first manned lunar landing, President Bush set forth the goal that the United States establish a permanent human presence in space. One of the initial milestones of this program is to be the establishment of a lunar base. Previous studies of advanced space systems (refs. 1 and 2) have identified non-terrestrial material utilization as a primary mission for a permanent lunar base. Specifically, lunarderived liquid oxygen (LLOX), which comprises $85 \%$ to $88 \%$ of the total requirement for space vehicles using hydrogen/oxygen chemical propulsion, can be used to support advanced space transportation systems. One limitation to this approach is the apparent paucity of lunar hydrogen. Preliminary system analyses (ref. 3) of the non-terrestrial propellant scenario indicate the utilization of LLOX with Earth-supplied hydrogen can be effective. When considering the export of LLOX by a lunar proximity transportation system, a significant portion is consumed in its delivery to lunar orbit. This quandary is a manifestation of the basic economic problem of the consumption of goods during delivery to the market. The reduction of this problem is the basic thesis of this study.

One approach to enhance the utility of LLOX is to employ a nonchemical method to achieve orbital or escape velocities from the lunar surface. One such method was the "mass driver" proposed by O'Neill (ref. 4) which would launch projectiles containing lunar regolith to a predetermined point in space. The payload cannisters are accelerated on recirculating buckets and collected by an on-orbit "catcher." This method requires a number of shots on the order of $10^{7}$ per year (due to small payload cannister capacity), an on-orbit LLOX production facility, plus the complex and poorly defined "catcher" system. Snow et al. (ref. 5) modified the O'Neill proposal of 
LLOX in a "smart" projectile (eliminating the requirement of the onorbit catcher). This method reduced the launches per year to the order of $10^{3}$, but the study did not assess the impacts to the space transportation system for the launcher's delivery and operation.

Subsequently, a 1986 NASA sponsored study at the University of Texas at Austin culminated in a conceptual point design of a passive coaxial acceleration (PCA) and the conclusion that a break even point for accumulated Earth-launched mass was obtainable within 12 years (ref. 9). This PCA design, however, requires the emplacement and construction of almost 2400 metric tons on the lunar surface, which is a prohibitive requirement to say the least. By using stateof-the-art composite materials and superconductors, Henry Kolm and his associates at EML Research, Inc. have proposed a preliminary design for a superconducting quenchgun that has a mass of about $10 \%$ of previous conventional PCA designs (ref. 6). This work, however, detailed a single point design for launching one metric ton LLOX payloads at intervals of two hours. This particular payload size and launch rate may not be the most practical to emplace with respect to LLOX demand, LLOX production, and delivery requirements. A method of scaling this design for different payloads and launch rates would yield a quenchgun better suited for a specific lunar evolutionary path.

This study is intended to deliver this needed parametric scaling analysis. It contains an overview of quenchgun geometry and operating principles, a definition of required support systems, and the methods used to size the quenchgun launcher and support systems. Also included is an analysis that assesses the impact a lunar quenchgun would have on the OEXPs Lunar Evolution Case Study.

LSPI has completed a FORTRAN model to perform a parametric sizing of an electromagnetic launcher with a LLOX payload range of 
one to twenty metric tons. Another FORTRAN model quantifies the necessary surface support systems to augment the sized electromagnetic launcher (EML). These two models have been integrated to create a complete EML and Systems Sizing Model, capable of delivering a detailed mass inventory of components to the lunar surface and annual resupply needs. The drivers required for the complete model are desired LLOX payload mass and launch rate, which are supplied interactively by the user. 


\section{MISSION DEFINITION}

The quenchgun launcher is to be located at the lunar equator and accelerate the LLOX payload to $1700 \mathrm{~m} / \mathrm{s}$, a value determined to minimize the delta-V required for circularization at a lunar altitude of approximately $100 \mathrm{~km}$. A small, solid-propellant apolune kick motor mounted on the payload canister will perform this burn. A $2^{\circ}$ launch angle with respect to the lunar surface is used to safely clear any lunar obstacles and to avoid impact with the launcher in the event the apolune burn does not occur. Since the proposed orbit has a period of roughly two hours, a launch interval which is a multiple of two hours will result in a "stockpiling" of LLOX payloads in the same orbital "slot" to facilitate retrieval operations.

The space transportation scenarios for launcher equipment and LLOX delivery plus the existing space infrastructure were defined during the preliminary design phase of the study and were kept as close to the Lunar Evolution Case Study (LECS) manifest as possible. The transportation scenario utilized the baseline low-earth orbit (LEO) node. An additional fully functional node in lunar orbit is advisable for safety and convenience, but is not a necessity. At the very least, a lunar orbit fuel transfer/fuel storage platform is required. A manned lunar base with a LLOX production facility was assumed to be functional along with space transportation vehicles capable of supporting such operations. Lunar Transfer Vehicles (LTVs) and Lunar Excursion Vehicles (LEVs) were used for orbitto-orbit and orbit-to-surface transfers, respectively. These vehicles were used for both cargo and crew transfer and have similar performance characteristics as those proposed for the Lunar Evolution Case Study.

Once in lunar orbit, the projectiles are recovered and returned to the orbiting fuel platform by remotely piloted or automated Orbital 
Maneuvering Vehicles (OMVs), which may be able to retrieve multiple payloads per mission. Once retrieved, the LLOX is stored. and transferred to spacecraft operating in lunar proximity. A periodic LEV flight would return empty projectiles to the surface for reuse. Figure 1 is a schematic showing the lunar proximity operations for the mission.

Figure 1: Schematic of Lunar Proximity Operations

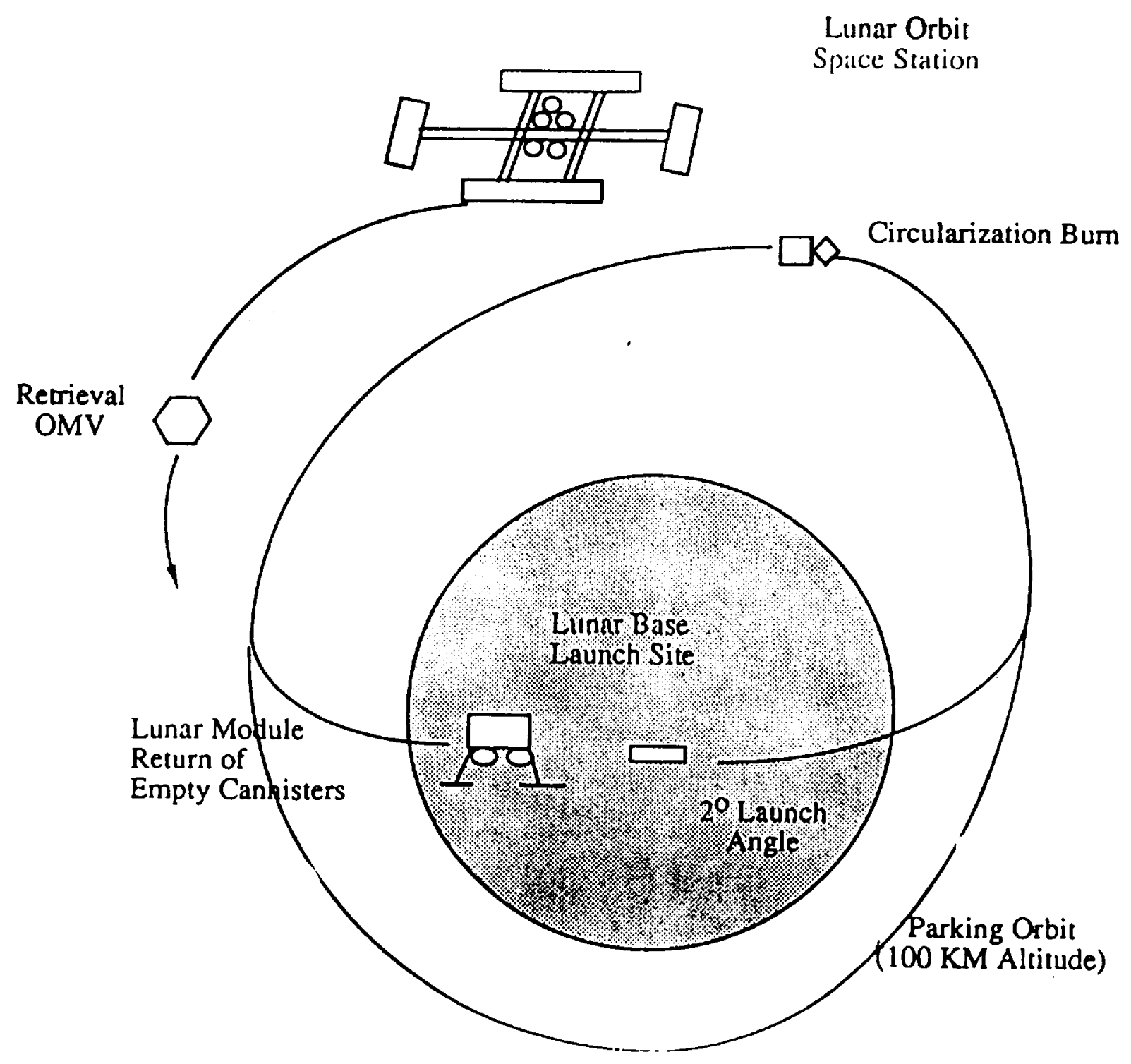




\section{QUENCHGUN DESIGN AND SIZING}

The concept of the quenchgun style launcher originated with an MIT research group in 1978 in the course of an exhaustive linear acceleration investigation sponsored by the Department of Defense. The nucleus of this group would subsequently form EML Research Inc., a private enterprise to further research the electromagnetic launch concept. The quenchgun design is not too far removed from the standard coaxial electromagnetic accelerator, or coilgun. Thrust is generated from the Lorentz force by passing a smaller charged projectile coil inside and through a larger current carrying barrel coil. Very large thrusts can be generated by this method if the current density in the barrel coils is sufficiently large and the coils are in close proximity. The proximity requirement implies that efficient acceleration would necessitate synchronizing the barrel coil current with projectile passage. In the standard coilgun application, the charge required for launch is stored in large capacitors, or similar devices, that have the storage time tuned to coincide with projectile passage. This time interval is equal to $L / R$, where $L$ is the inductance of the coil and $\mathrm{R}$ is the resistance of the material. Capacitors, however, have a low energy density and incur significant losses when very large charges must be stored. By using presently available superconductors to store the launch energy rather than capacitors, the entire amount can be stored in the barrel and transferred to the projectile almost completely without loss. This is provided that a few simple conditions are met. The first condition is that the long solenoid barrel be divided into a number of shorter current carrying coils. These current carrying barrel coils must be open-circuited at the instant of projectile passage to prevent reintroduction of current to each coil. Furthermore, if the projectile coil carries just enough current to induce a current zero in each barrel coil as it passes, then the projectile will absorb all of the energy originally stored in the barrel without loss.

The three main stages of the launch sequence are shown schematically in Figure 2. In Figure 2a, the projectile is initially 
current free as it rests in the breech, and need not be superconducting, so long as its $L / R$ time constant is greater than the launch duration. To initiate launch, the injection coil is quenched, which transfers the current to the projectile coil, as shown in Figure 2b. The projectile is then pulled into the barrel by the force of mutual induction, as shown in Figure $2 c$, and accelerated as it passes each barrel coil. The projectile will leave the muzzle of the gun with all of energy initially stored in the barrel, to within the accuracy with which the current zero state is satisfied at each barrel coil. The barrel coils may be charged in a steady state manner and in series to minimize the required current, but they must be disconnected prior to launch.

a)

FULY CWAGE AFNOY TO FRE

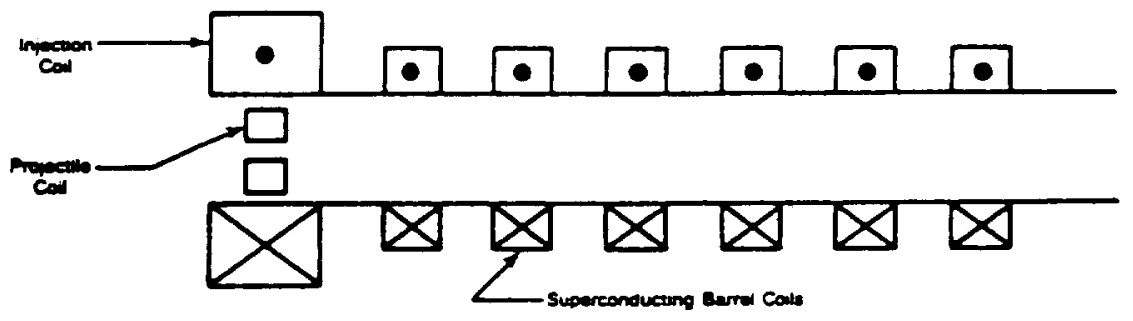

b)

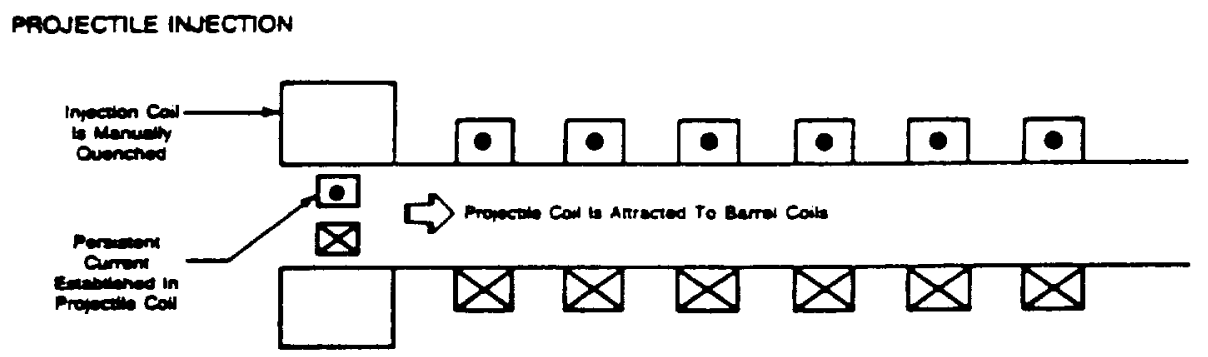

c)

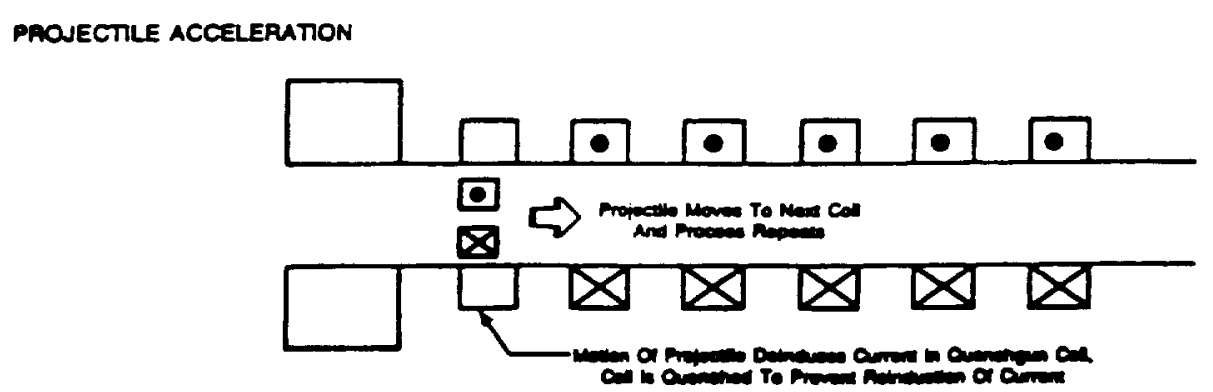

Figure 2a-c: Quenchgun Launch Sequence 
The actual design of the gun takes advantage of several still emerging advanced technologies. These include the use of high technology composites and low temperature superconductors. The gun barrel is composed of individual modules, each of which has a mass of $750 \mathrm{~kg}$ and a length of $0.5 \mathrm{~m}$. A section of a barrel module is shown in cutaway in Figure 3. The inner section consists of the superconducting barrel coils, the dimension of which depends on the desired payload to be launched. With the present state of superconducting technology, these barrel coils must be refrigerated to a temperature of about $4 \mathrm{~K}$ in order to preserve the resistance free property. In the design presented in this study, this refrigeration is accomplished by a forced flow of supercritical helium through small stainless steel tubing. Stainless steel was selected because of its good strength-to-mass ratio and other material properties at cryoten temperatures such as being non-magnetic. Neighboring modules are separated by circumferential inner flanges, which are rigidly connected to each other by 16 draw bolts. These draw bolts must carry the compression force necessary to counter the recoil force and prevent the individual modules from separating elastically during recoil. Recoil forces in the quenchgun appear locally at each module as the projectile passes, and are thus more equitably distributed than in a conventional chemical gun.

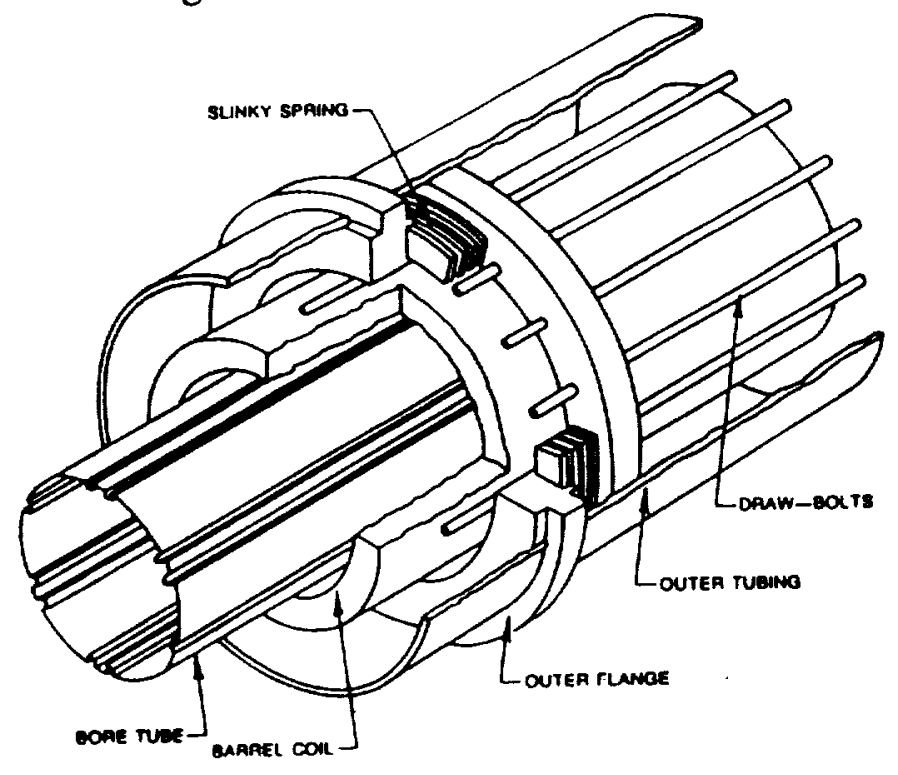

Figure 3: Cutaway View of Barrel Module 
The outer section consists of tube segments which have the same spacing as the inner flanges and is at ambient temperature. Efficient insulating material, such as aluminized Mylar is packed loosely into the space between the flanges. The heat leak through this type of super-insulator is considered negligible. The warm outer section and cold inner section are connected by cylindrical "slinky" springs, which are manufactured of fiber reinforced composite to avoid induced voltages. These provide sufficient support to compensate for lateral forces while allowing the inner section to recoil. During the instant of recoil, the inner flanges transmit strong axial forces to the outer flanges through the fully compressed springs. This causes a temporarily high heat leak, which should not dominate the analysis unless the oxygen payload were large and the EML were fired frequently. The main source of heat loss is the steady conduction through the springs.

The proposed design makes generous use of the availability of practical and relatively inexpensive fiber reinforced composite materials, which are well suited to the environment of the lunar surface. The inner barrel tube, the outer tube, and all flanges are of this high strength material. The only metal components of the launcher barrel are the draw bolts, stainless steel refrigeration tubes, and the accelerating coils themselves. Metal cannot be used too near to the barrel coils because it could carry very high induced circumferential currents.

The projectile itself has four major constituents: the payload canister, the armature ring, the avionics package, and the apolune kick motor. Ideally, the payload canister should be constructed from a non-conducting, high strength material, such as fiber reinforced composite. It has roughly the same geometry and design as a standard pressure vessel. The armature ring is what actually interacts with the barrel coils and pushes the projectile as it accelerates down the barrel. It consists of an aluminum alloy ring that serves as a single turn projectile coil. This type of alloy, if 
precooled to approximately $80 \mathrm{~K}$ will have a $\mathrm{L} / \mathrm{R}$ time constant in excess of the launch duration. This alloy ring is surrounded by a reinforcing graphite stress hoop and is configured with a set of six guide ribs which fit into slots in the barrel during acceleration. The projectile dimensions, minus avionics package and kick motor, for a $1000 \mathrm{~kg}$. LLOX payload are shown in Figure 4. The solid propellant kick motor and the avionics package are located at the muzzle end of the projectile and must be able to withstand an acceleration in excess of 1000 times that of Earth's gravity. The LLOX canister and armature are rigidly attached and launched into orbit together. A decelerator to keep the armature in the barrel and a retrieval mechanism to return it to the breech would add considerable complexity and increase the system mass by roughly $30 \%$.

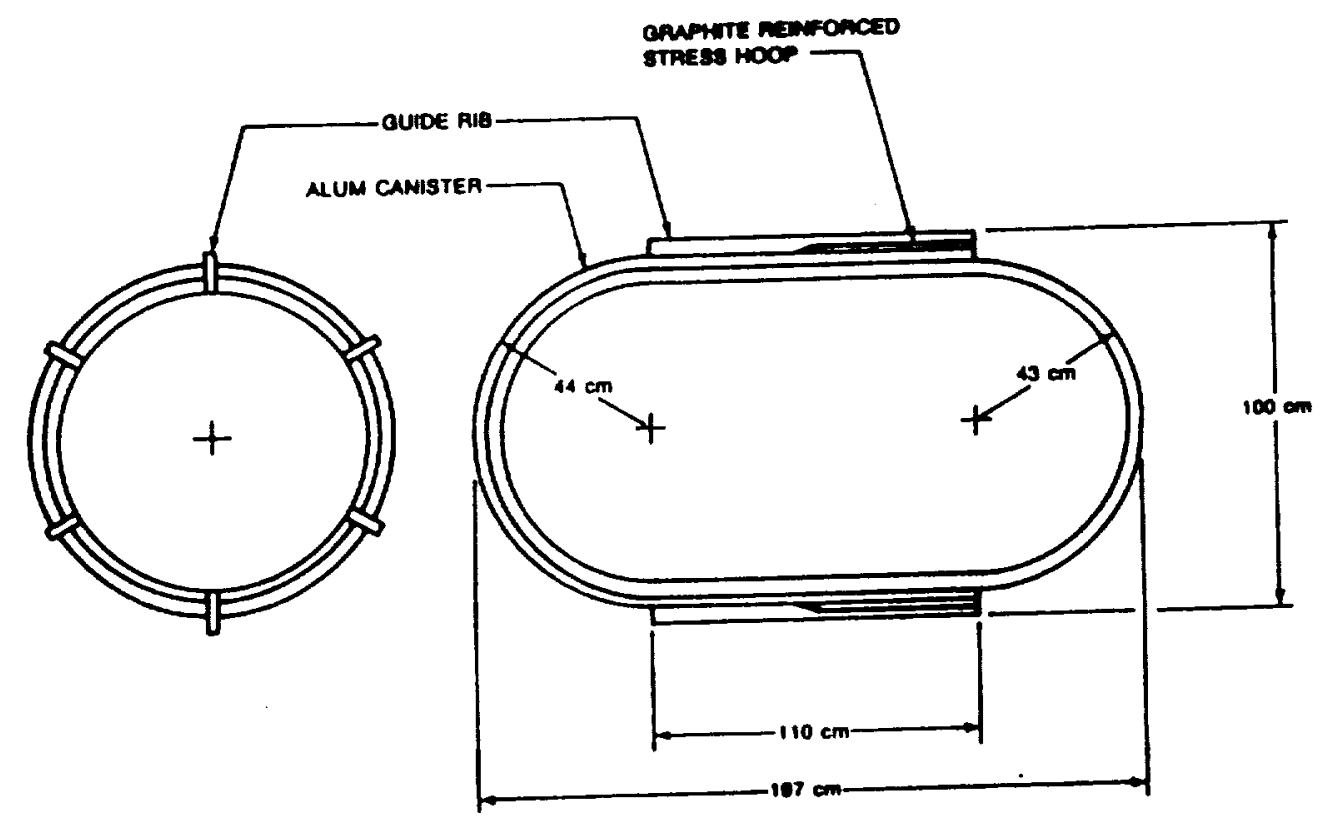

Figure 4: Projectile Dimensions for $1000 \mathrm{~kg}$ LLOX Payload

In order to quickly and efficiently generate important parameters for launchers of different sizes, a launcher sizing subroutine was constructed. This FORTRAN subroutine, titled "EMLSIZE", calculates the mass of the EML system components and the steady state charging power required for launch. The required model drivers are: LLOX payload in metric tons and launch interval in hours. The model consists of scaling relations suggested by EML 
Research (refs. 6 and 7). The point design presented in ref. 6 hinged in the consideration of four critical design parameters:

- hoop stress in the barrel assembly,

- hoop stress in the armature,

- hoop stress in the LLOX payload canister, and

- net heating of the armature during launch.

The maximum allowable values for these parameters were used to develop the single point design. In ref. 7 , these parameters were kept constant at their near maximum values to insure the same level of design optimization during sizing. The diameter of the barrel was the variable which governed the values of other parameters in the launcher sizing algorithm. In the FORTRAN scaling model it was desired to use the LLOX payload mass as the independent variable to subsequently determine the barrel bore diameter. Quantitative relations for barrel mass, armature mass, projectile acceleration, barrel length, and launch energy with respect the diameter were derived from the five EML point designs that were supplied between refs. 6 and 7. A tabular summary of these designs are contained in Table 1. A comparison between the original data and points on the derived curves show differences that range from 0.0 to 3.85 percent. It should be noted that these scaling relations lose their accuracy as the oxygen payload decreases below one metric ton.

Table 1: Summary of Quenchgun Point Designs

$\begin{array}{llllll} & \text { Case 1 } & \text { Case 2 } & \text { Case 3 } & \text { Case 4 } & \text { Case 5 } \\ \text { LLOX Payload (MT) } & 1.00 & 1.37 & 2.00 & 5.00 & 10.00 \\ \text { Barrel Mass (MT) } & 212 & 290 & 423 & 1058 & 2120 \\ \text { Armature Mass (MT) } & 0.26 & 0.36 & 0.52 & 1.31 & 2.63 \\ \text { Acceleration (gees) } & 1150 & 973 & 819 & 514 & 362 \\ \text { Barrel Length (m) } & 147 & 172 & 207 & 329 & 465 \\ \text { Launch Energy (GJ) } & 1.82 & 2.50 & 3.64 & 9.12 & 18.2 \\ \text { Barrel Bore (m) } & 0.92 & 1.00 & 1.10 & 1.38 & 1.64\end{array}$


Figure 5 is a flowchart which indicates the solution sequence in the FORTRAN launcher sizing model, "EMLSIZE".

Some of the other associated EML system components are sized in "EMLSIZE" in accordance with the guidelines suggested in ref. 6. The power controller mass is directly proportional to the length the launcher barrel, and is governed directly by the number of coils. From the point design in the same document, the barrel was $150 \mathrm{~m}$ in length, and the power controller had a mass of 0.5 ton. The power consumed by the power controller is assumed to remain constant and to have a nominal value of $5 \mathrm{~kW}$. The mass of the barrel support structure is a parameter that increases linearly with the number of barrel coils required, which is directly related to the length of the barrel. A support structure of $83.33 \mathrm{~kg}$ was required for each 750 $\mathrm{kg}$ barrel coil, which is $0.5 \mathrm{~m}$ in length. The payload injector that loads the canister and armature into the breech is allowed to increase linearly with the payload mass. Taken from ref. 6 data, the injector to payload ratio is $3: 1$. The power required by the injector is assumed to scale in the same linear fashion at $5 \mathrm{~kW}$ per $1000 \mathrm{~kg}$ of LLOX payload. The central control center for the EML system is housed in a free standing structure, modeled as a lunar base habitat with a mass of $11,700 \mathrm{~kg}$ and a power consumption of $75 \mathrm{~kW}$. The annual resupply mass for the EML are broken down by component as a percent of original emplacement mass for that component as follows: $5 \%$ for the least dynamic and most reliable components, such as the barrel and the barrel structural support; $10 \%$ for the more mechanical and less reliable systems, such as the payload injector, control center, power controller, and surface rover; $20 \%$ for the payload canisters and armatures. 
Figure 5: Launcher Sizing Model Solution Sequence

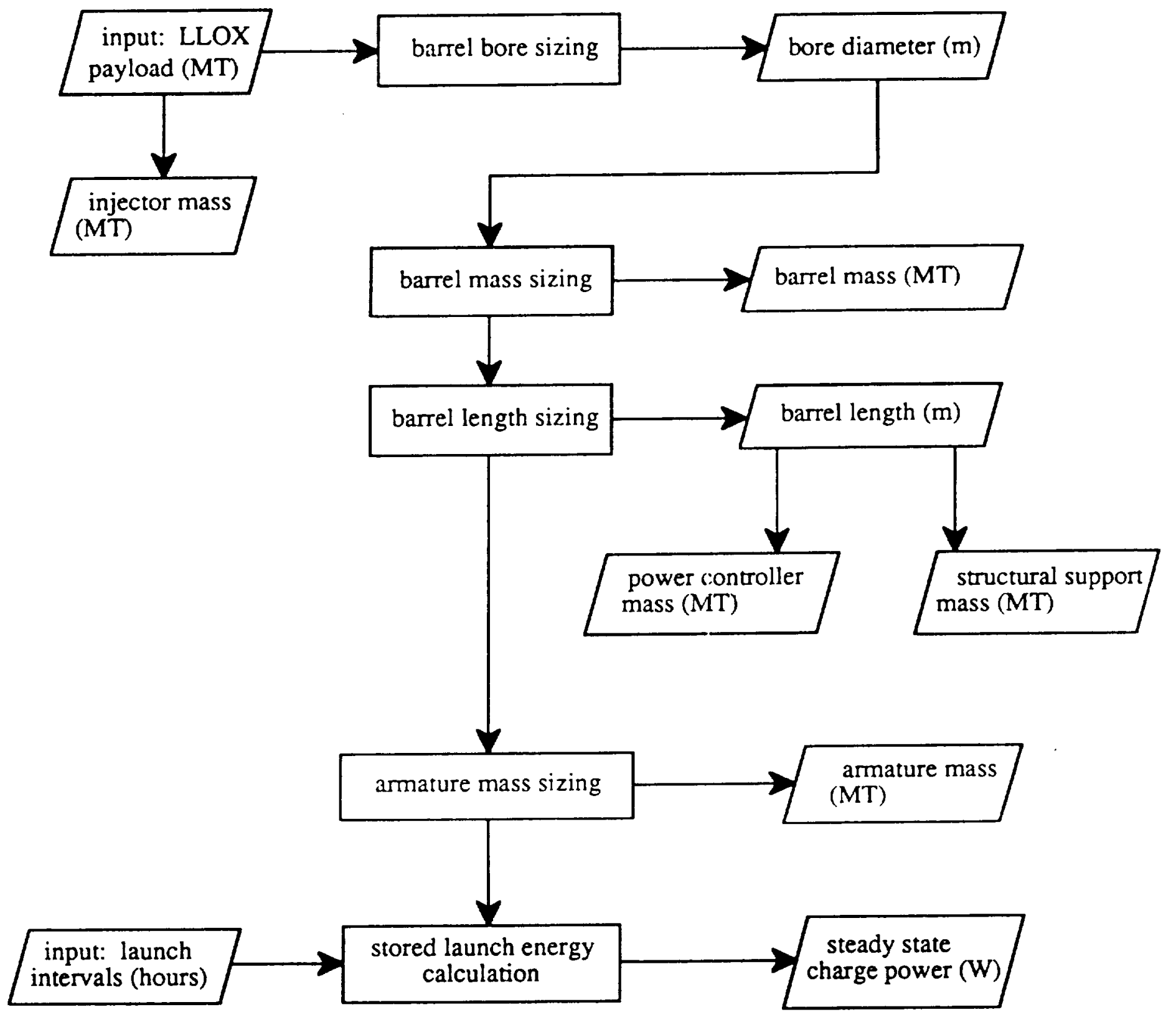




\section{SUPPORT SYSTEM COMPONENTS AND SIZING}

The surface support systems necessary to maintain the lunar quenchgun as a separate entity from other lunar surface activities can be itemized in the following categories: barrel coil refrigeration, power generation, power system thermal control, operations, and surface preparation and construction equipment. The heavy equipment necessary to emplace the launcher on the lunar surface are assumed to be in place by the time the launcher construction period begins. The drivers for the sizing of surface support systems are the launch system attributes that result from the EML sizing model: barrel mass and power required by the quenchgun and associated systems. The Support System Model, "SUPPORT", is divided into subroutines dedicated to each of the various support subsystems. The power required by the EML refrigerator is an input for the subroutine "POWER", which sizes a power generation and conversion system to supply the refrigerator and to charge the EML. The excess heat rejected by the sized power system is the input for the subroutine "POWERTC", which calculates the power required by the thermal control system to dissipate the rejected heat. This power is then added to the EML and refrigerator power and the power generating system is resized. This process is repeated until convergence of power required and power generated is obtained within a specified convergence criteria (10 watts). If convergence is not obtained a diagnostic message appears and the program stops execution.

The superconducting coils in the barrel must be kept at $4^{\circ} \mathrm{K}$ to preserve the resistance free property. The subroutine "EMLREF" sizes a refrigerator to cool the superconducting coils and associated elements. The amount of cold mass in each barrel module is approximately $80 \%$ of the module mass. The heat that the refrigerator removes from the EML barrel is due primarily to a steady-state heat leak through the fiber-composite cylindrical springs that connect the inner and outer sections of the barrel assembly. This leak is approximated as one watt for each $1000 \mathrm{~kg}$ of 
cold mass at earth gravity. It is assumed this value scales directly with weight of the cold mass to be supported to $1 / 6$ watt per 1000 $\mathrm{kg}$ cold mass at the lunar surface. The heat leak is a function of the weight loading of the cold mass, thus, the flux through the thermal path is a function of the gravity environment.

The scaling relations for the refrigerator are taken from the original paper completed by EML Research Inc. The mass of the refrigerator can be attributed to two main sources: the refrigerator compressor and the radiator, with the compressor dominating the power and mass requirements of the refrigerator. The power supplied to the compressor is one $\mathrm{kW}$ per $\mathrm{W}$ lost at $4^{\circ} \mathrm{K}$. The refrigerator technology used in this study had a mass multiplier of $25 \mathrm{~kg} / \mathrm{W}$ where the power required is that of the compressor. Per reference 8 , the radiator has a mass multiplier of $0.02 \mathrm{~kg} / \mathrm{W}$ of rejected heat when operated at the rejection temperature of $300^{\circ} \mathrm{K}$. The annual resupply mass for the refrigerator was estimated to be $10 \%$ of its total emplacement mass.

To be completely independent of other lunar activities, the lunar quenchgun must have its own power source. The subroutine "POWER" sizes a power generation system and a power conversion system based on total power required by the EML and the technology choice is specified by the user. The mass required for power distribution and the annual resupply mass for the entire system is calculated. The four generation options provided are Photovoltaic Silicon, Photovoltaic Gallium Arsenide, Solar Dynamic, and Space Power (SP) Nuclear. The four conversion technology options considered are Brayton, Stirling, Thermionic, and Rankine. If the power requirement is larger than the maximum unit size for the chosen generation type, then multiple units of the maximum size are used.

The coefficients used in the parametric sizing equations are stored in columnwise format in data file SUPPORT.DAT, with relevant comments to the right. This can be seen by referring to the attached 
copy of SUPPORT.DAT in Appendix I. When a generation type is chosen by the user, the proper coefficients are loaded into a $7 \times 3$ matrix GDAT. Each of the first five rows of this matrix contains three constants, $\mathrm{C} 1, \mathrm{C} 2$, and $\mathrm{C} 3$, used in a different calculation. The equations are of the form: $(\mathrm{Cl})^{*}(\text { unit power })^{(\mathrm{C} 2)}+(\mathrm{C} 3)$. Where unit power is either the total power required or the maximum power per unit for the generation type, in watts. The sixth row contains the resupply coefficient, efficiency, and generator rejection temperature. The purpose of each coefficient is clearly labeled in the source data file. The coefficients for the conversion unit sizing are read from the same data file into a $3 \times 3$ matrix called CDAT. The first two rows of constants are used in formulas of the same format as above, while the third row contains the resupply factor, efficiency, and conversion cycle rejection temperature.

For the distribution calculation the necessary coefficients are loaded from SUPPORT.DAT into a 4 element vector called DDAT. The first 3 coefficients are used in a relationship with the same format as before, but instead of using the unit power as the base for the exponent, distance from the generator is used. The EML is considered to be an independent site at a distance of 100 meters from the power supply. The fourth coefficient is the distribution resupply factor. It should be noted that the distribution system mass and resupply are independent of the generation and conversion type.

Certain of the generation technologies, notably the Solar Dynamic and SP Nuclear, produce excess heat as a by-product of their operation. The subroutine "POWERTC" calculates the mass, power requirements, and radiator specifications of the thermal control system that dissipates the heat rejected by the generation and conversion cycles. A thermal control power factor of $0.05 \mathrm{~W} / \mathrm{W}$ is used. This implies that the thermal control system will require one watt of power to handle and reject 20 watts of excess heat. If the generator rejection temperature is greater than $400^{\circ} \mathrm{K}$, for SP Nuclear generation, the specific radiator mass increases from $3.43 \mathrm{~kg}$ per 
square meter to $6.86 \mathrm{~kg}$ per square meter. This is due to the switch to a higher density heat transfer medium, which, in turn, requires modified circulation equipment. In addition, the heat transfer system mass increases from $158 \mathrm{~kg}$ to $316 \mathrm{~kg}$ at the same threshold. Figure 6 is a schematic of the power and heat flow between the components of the entire launcher system. Figure 7 is a flowchart that details the sequence of solution in the Support Systems Sizing Model. For this system the annual resupply mass is assumed to be $20 \%$ of the total emplacement mass.

Required crew, repair, and routine inspections are considerations necessary for normal operations of the lunar quenchgun. For an EML that launches $1000 \mathrm{~kg}$ payloads at two hour intervals, it is estimated that a crew of four can offload, emplace, assemble, and operate the launcher. If considerably larger designs are desired, the increased number of barrel modules and support equipment imply the construction period would have to be increased. It is proposed that these EML dedicated crew members reside at the permanent lunar base and commute to the launcher site. During delivery and construction, all four of these personnel would be working the same shift hours. During normal operations, however, two on duty at a time should be sufficient to oversee the EML. All manipulation of the payload canisters between the LLOX filling station and the launcher injector is assumed to be automated.

For convenience and safety, all but the simplest repairs should be limited to replacement of the defective component. This requires that the final designs for modules and their components should be field replaceable. One part of the launcher which may be prone to failure is the ribbed bore tube manufactured of fiber reinforced composite. This wear is due to incidental contact with the armature guide fins during launch. Another component which should be inspected regularly are the composite springs which contract to absorb much of the recoil. The primary wear prone parts of the projectile are the six armature guide fins. 
For stress induced fatigue considerations, the fiber reinforced composites in the EML can be comparable to composite helicopter rotors, which are acceptable for 50 to 100 operating hours between comprehensive inspections. This corresponds to between 500,000 and 1,000,000 stress reversal cycles. It is conservative to assume that similarly loaded parts of the EML can be expected to perform on the order of 10,000 launches between failures. 
Figure 6: Support Systems Power and Heat Flow Diagram

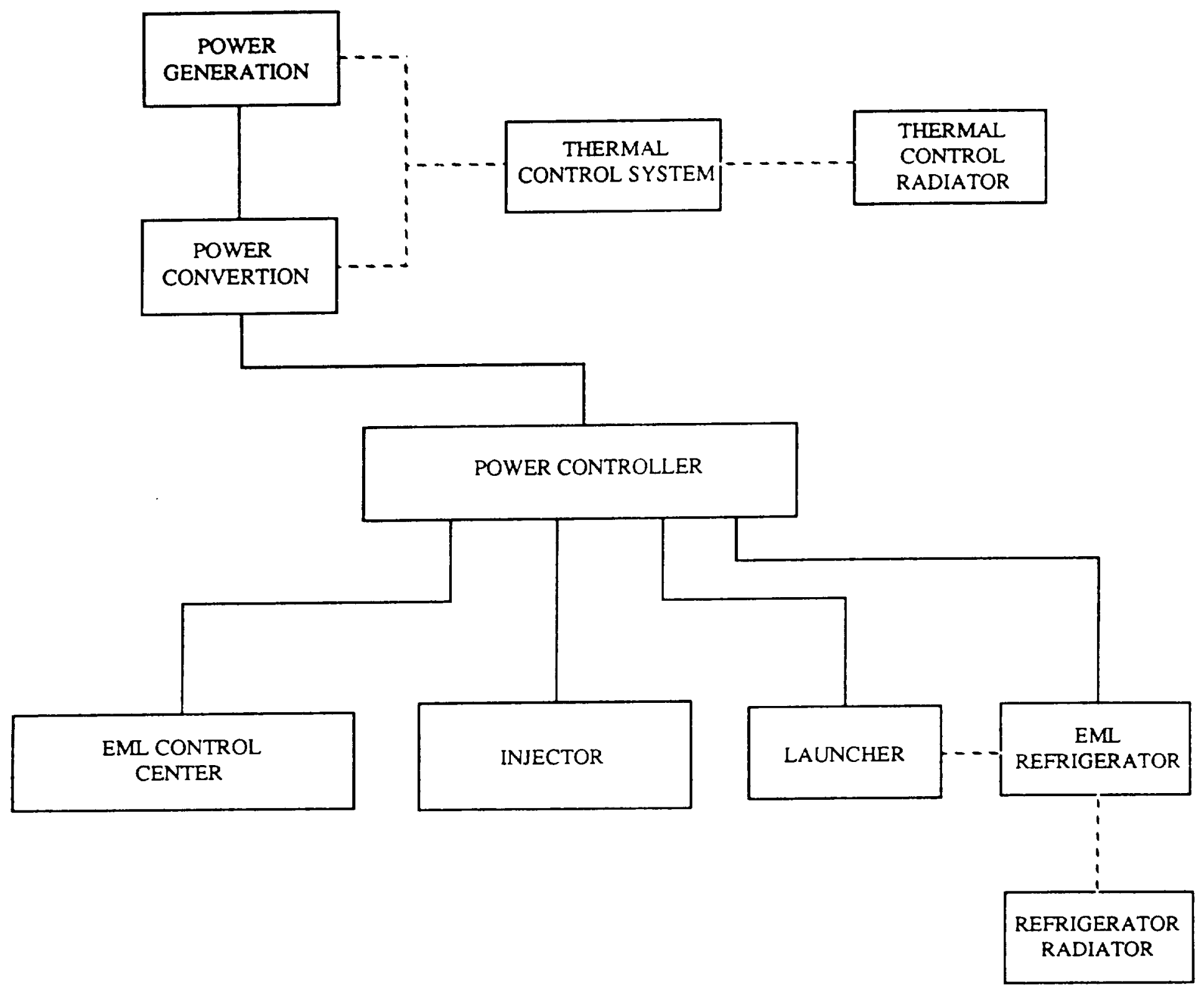

POWER FLOW:

HEAT FLOW: 
Figure 7: Surface Support Systems Model Solution Sequence

Subroutine

REFLBM

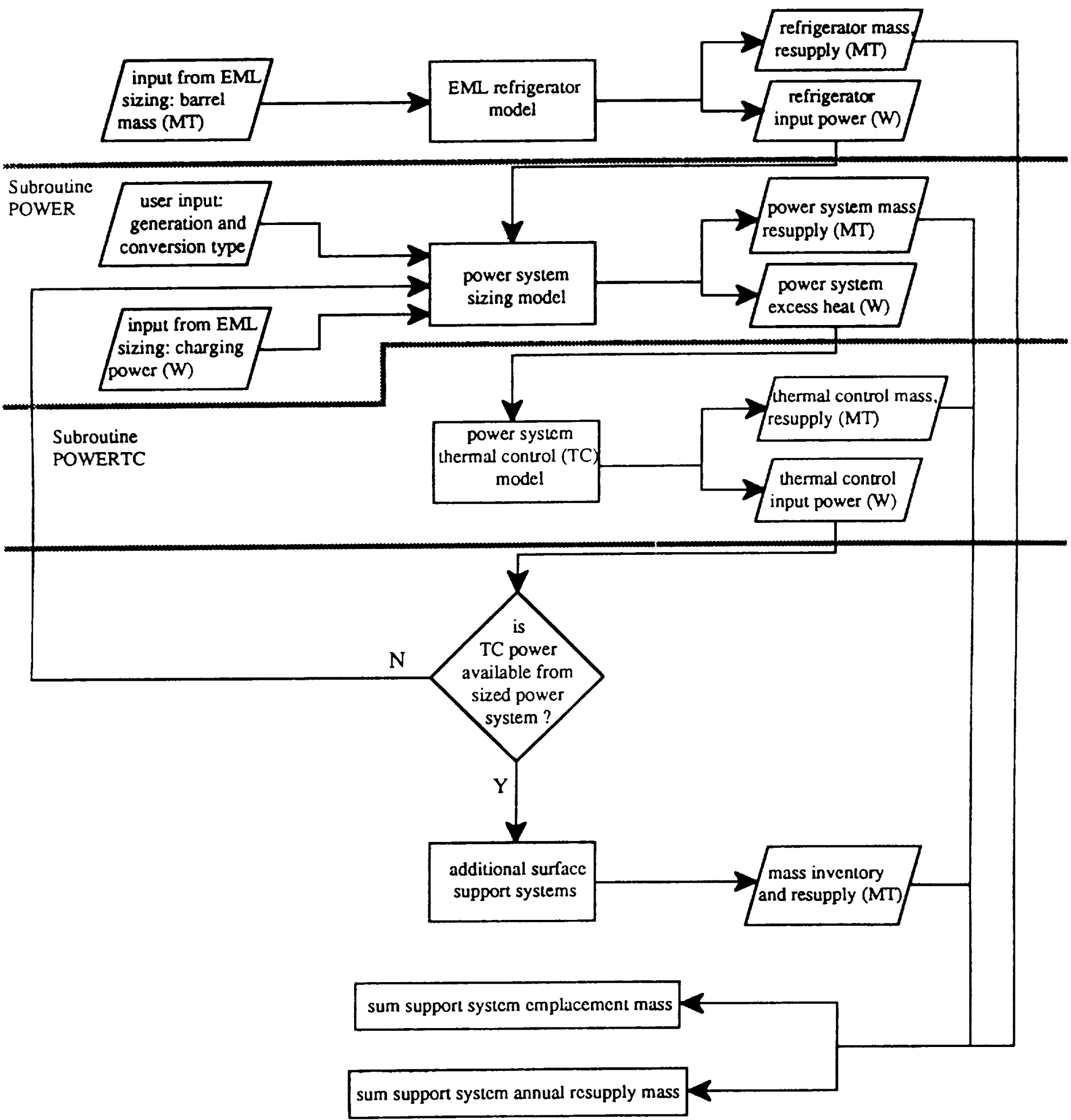




\section{INTEGRATED LAUNCHER AND SUPPORT SYSTEM MODEL}

The two autonomous subroutines to size the lunar quenchgun and surface support systems are integrated into a single FORTRAN model, "EMLMOD". This is done to give the user greater flexibility when sizing the systems over a range of variables. The two programs interfaced since the output from the quenchgun sizing program contains the required input for the support system sizing. As a result, no additional information is required from the user. The overall system driver remains the desired LLOX payload in metric tons and the desired launch rate in hours.

The most vital information provided by the model, such as emplacement mass and annual resupply mass for the EML, support systems, and complete integrated system are printed directly to the screen at the conclusion of the program. A more technically detailed data inventory is written to two associated output files: EML.OUT for EML data and SUPPORT.OUT for support system data, and is available to the user at the end of the program run.

This integrated launcher and support system model allows quick comparison between designs and is easily interfaceable with other programs to allow analysis for the lunar quenchgun as a stand alone objective. The FORTRAN source code is contained in Appendix $I$ and is documented internally so that the user can follow program calculations in detail. The program takes only seconds to run, but the values for the LLOX payload and launch interval must be entered interactively during each run. 


\section{TRANSPORTATION AND LOGISTICS MODEL}

It was desired to see the impact a quenchgun would have on the Lunar Evolution Case Study (LECS). This analysis requires the delivery of approximately 270 additional metric tons of cargo to the lunar surface. Needless to say, this would increase the burden on the cislunar transportation system. A tool to determine the optimal transport scenario for each year was required. The Transportation and Logistics Model was conceived to perform this task.

The amount of hydrogen and oxygen required for cargo or crew delivery is a non-linear function of the amount of payload mass carried per individual flight. This non-linear system, when considered as a whole, does not easily yield itself to numerical optimization. A few simplifying assumptions were made in order to reduce this non-linear system to a more numerically attractive linear model. The first is that the payload and structural mass of each vehicle will remain constant over each year, but can be updated on a year to year basis. A second assumption is that each vehicle will depart at full payload capacity for each flight. These two requirements allow one to consider each vehicle to have a constant fuel consumption per flight for a given year. These assumptions reduce the non-linear system to a simplified linear system.

In the formulation of this model, five types of vehicles were considered. Four of these are similar to those found in the Lunar Evolution Case Study: Lunar Excursion Vehicles for cargo and crew (LEV-C and LEV-P, respectively) stationed on the lunar surface for surface-to-orbit operations, and Lunar Transfer Vehicles for cargo and crew (LTV-C and LTV-P, respectively) stationed in LEO for orbit-to-orbit operations. An additional vehicle, an Orbital Maneuver 
Vehicle (OMV) was required to retrieve the LLOX payload cannisters launched by the quenchgun. All of the vehicles in the model have strictly chemical propulsion, and unless otherwise available, the oxidizer to fuel mass ratio was assumed to be $6: 1$.

The mathematical system is then formulated with the desired cargo mass and the number of crew to be delivered to the lunar surface each year as the model drivers. This data governs the number of LEV-C and LEV-P flights. These two vehicle flight requirements give an amount of fuel which must be available in the lunar vicinity. Including lunar surface LLOX production and an operative quenchgun, the LOX portion of this fuel can have three points of origin: 1.) the Earth, as cargo aboard a LEO-based LTV-C or LTV-P; 2.) the lunar surface, available to the landers on the lunar surface; 3.) the lunar surface, available in lunar orbit after launch by EML and retrieval by OMV. The optimality of the solution depends on the proper amount of LOX being delivered from the proper combination of these points of origin. Once the amount of LOX required from the lunar surface is resolved, the remaining amount is of Earth origin and must be delivered as cargo aboard orbital transfer vehicles flights. The number of these flights, in turn, determine the flight requirement from Earth to LEO.

This entire transportation system can be modeled by a complex system of interdependent FORTRAN DO-loops with branches satisfying various logical conditions. An alternative approach that is more cost effective and more appropriate to the problem at hand is to apply a linear programming optimization technique which allows certain variables (such as number of flights for each vehicle) to increment by only integer values. The software employed is commercially available and utilized the modified simplex matrix method with a branch and bound technique to investigate integer 
solutions of the linear system. In formulating the initial conditions for each year, the user can choose the LOX origin points to be 'on' or 'off in any combination. The objective equation to be minimized was the sum of fuel required of each vehicle, or total fuel of the system, regardless of origin. This equation was minimized subject to an array of equalities and inequalities that specify fuel origin, LOX available from the lunar surface, individual vehicle payload, and performance specifications.

By using this method, the minimum annual flight requirement for the vehicle fleet was obtained given annual delivery rates of cargo and crew to the lunar surface. This transportation and logistics model was used to analyze the impact that the delivery and emplacement of an EML would have to the Lunar Evolution Case Study in terms of individual vehicle flights, LOX, LLOX, and mass to LEO. 


\section{LOCAL EVALUATION WITH LUNAR EVOLUTION CASE STUDY}

The Transportation and Logistics Model described in the previous section was used in conjunction with the OEXP Lunar Evolution Case Study (LECS) surface manifest to determine the impact of an EML on the transportation requirements outlined under the study. The LECS surface manifest has undergone frequent changes. The one considered for this study was generated on July 11,1989 at 1:40 p.m. Table 2 contains a summary of the LECS that was used, detailing cargo and crew to the lunar surface per year. Delivery to the lunar surface begins in September 2003 and culminates on January 2015. Surface LLOX production is initiated in 2010 by a pilot production plant with a LLOX production capacity of $24 \mathrm{MT} /$ year. By 2012, three more plants of this same design have been delivered to boost the total LLOX production to $96 \mathrm{MT} / \mathrm{year}$. This plateau, however, is where this version of the LECS surface manifest concludes it's LLOX production considerations. LLOX processing on this scale certainly does not warrant the introduction of a massive EML to export excess LLOX from the lunar surface. To examine large scale exportation of LLOX and fully evaluate the impact of an EML on the evolution of a lunar settlement, the LLOX production on the surface must be increased. For this analysis, the LECS surface manifest was modified to accommodate this increased LLOX production by extending the evolutionary test period by three years to 2018, attaining peak LLOX production in 2017.

The lunar quenchgun and associated support equipment would be delivered evenly over the period of two years, 2011 and 2012 . Operative status for the launcher is commenced in 2013. From the years 2013 to 2017 cargo delivery to the lunar surface included additional LLOX production equipment, quenchgun resupply, and the 
nominal annual delivery of $25.6 \mathrm{MT} / \mathrm{yr}$ indicated in the LECS surface manifest for years following 2013. The results obtained for 2018 are considered typical for years following 2018 at maximum LLOX production and export capacity. The crew required on the surface each year following 2010 was increased by four persons to account for the additional EVA and IVA to off-load, construct, and operate the extra equipment associated with the lunar quenchgun.

Table 2: Summary of Lunar Evolution Case Study

$\begin{array}{ccc}\text { Year } & \text { Cargo }(\mathrm{MT}) & \text { Crew } \\ 2003 & 36.8 & 0 \\ 2004 & 44.6 & 8 \\ 2005 & 47.0 & 4 \\ 2006 & 45.3 & 4 \\ 2007 & 47.0 & 4 \\ 2008 & 33.0 & 4 \\ 2009 & 44.3 & 4 \\ 2010 & 41.5 & 4 \\ 2011 & 43.6 & 4 \\ 2012 & 49.4 & 8 \\ 2013 & 24.9 & 4 \\ 2014 & 25.6 & 8 \\ 2015 & 25.6 & 4\end{array}$

Three case studies were considered using the modified LECS surface manifest: one case each for low LLOX production (96 MT/year), intermediate LLOX production (300 MT/year), and high LLOX production (600 MT/year). The relevant system parameters used for comparison included mass delivered to LEO, required surface-to-orbit and orbit-to-orbit flights, and liquid oxygen 
required from Earth and the lunar surface. During the enhanced LLOX production period, it is assumed that up to $85 \%$ of the LLOX produced is available for export to lunar orbit, or is available to the vehicles stationed on the lunar surface.

A minimum system mass criterion was used to choose the quenchgun design to be used in each case study scenario. The dominating factor in quenchgun and support system mass is the quenchgun barrel mass, which increases exponentially with respect to the payload. The minimum quenchgun mass, then, is found when the payload mass is at the minimum allowable value, which is one metric ton. The support systems in each case were sized to allow for quenchgun delivery of all the LLOX produced in the peak production years. The OMVs located in lunar orbit are assumed to retrieve two canisters per flight.

There are several important considerations that must be investigated if the quenchgun equipment is to be delivered over a period of two years. Perhaps most important are the cyclical stresses in the equipment on the lunar surface due to heating/cooling during the lunar day/night. Secondly, possible hazards of the lunar environment, including damage resulting from surface dust or micrometeorites, should not be ignored. Also, radiation encountered over a period of years could serve as a catalyst for material flaws and cause the onset of metallic brittleness. For this delivery scenario, it is assumed that the danger posed by these obstacles can be minimized through simple shielding, if deemed necessary.

The results of this impact analysis indicate that a quenchgun coupled with the low LLOX production rates in the present Lunar Evolution Case Study would be far from optimal, even prohibitive, while the high production rate of $600 \mathrm{MT} / \mathrm{yr}$ could enhance the lunar 
transportation system. Figures 8 through 12 detail the findings of the impact analysis. The delivery requirement increases for all the quenchgun utilization cases. The LLOX production in all but the high production case is insufficient to support the entire oxidizer requirement of the transportation fleet. For the high production case, the cislunar transportation system will achieve liquid oxygen independence in 2018, assuming a constant surface manifest continues. The mass delivered to LEO may decrease by as much as $30 \%$ in the years following 2018 as a result of this independence.

Figure 8 shows the Earth LOX requirement over the entire case study period, from 2003 to 2018 . Since quenchgun delivery does not begin until 2011 , the requirement from 2003 to 2010 is the same as in the LECS. The years 2011 and 2012, however, require a high investment period to deliver the quenchgun system, which has a mass of approximately 270 metric tons. The different quenchgun sizes required for the different cases do not vary enough in mass to require sufficiently different transportation requirements. The LOX requirement during the years 2013 to 2017 increases due to the delivery of additional LLOX production equipment, EML resupply, and increased crew size. Considering just the three impact studies, it is clear that the Earth LOX requirement is consistently driven down as LLOX production increases. This is most readily seen in the high production case, where the Earth requirement is eventually driven to zero in 2018. The years 2014 and 2016 appear to defy this trend, but the amount of LLOX equipment needed to attain $600 \mathrm{MT} / \mathrm{yr}$ require additional flights by the LEV-C and LTV-C. The heavy initial investments of 2011 and 2012 eventually show some return in 2018 as the cislunar transportation system gains LOX independence.

The flight requirement between the lunar surface and lunar orbit is shown in Figure 9. For all cases the delivery schedule 
remains the same as in the LECS for the years preceding 2011. As LLOX production increases and eventually peaks in 2017, the number of surface-to-orbit flights for EML support becomes dominated by the flights needed to return payload canisters to the surface. The greatest increase is for the high LLOX production scenario, where an additional seven flights per year are required for the years 2016 and 2018. This high flight requirement is prohibitive for a number of reasons. One is the increased wear to the vehicles, which would result in more frequent servicing or replacement. Secondly, increasing the number flights increases the likelihood of a transportation accident. The final consideration is the extra fuel that these additional flights would require in lunar orbit. This demand is great enough, in fact, to require an additional LTV-C flight for the purpose of fuel delivery. This can be seen in Figure 10 for the years 2014 and 2016. The number of orbit-to-orbit flights for 2018 drops to two because the delivery to the lunar surface no longer includes LLOX production equipment. The delivery to the lunar surface is assumed to continue at the same rate after 2018 , so it can be expected that one additional transfer vehicle flight and up to seven additional lander flights per year are required for out year considerations.

Figure 11 is an overlay showing the total amount of LOX required by the transportation system versus the amount delivered from Earth for this version of the OEXP's Lunar Evolution Case Study. Prior to the year 2013, all the LOX used must be of Earth origin. In 2013 LLOX production is peaked at the rate of $96 \mathrm{MT} / \mathrm{yr}$ and it is utilized at the rate of $41.6 \mathrm{MT} / \mathrm{yr}$. Although this LLOX utilization partially reduces the burden of lifting oxygen from the Earth, a strong dependence still exists. Figure 12 demonstrates how the LOX umbilical cord is severed for the high LLOX production scenario, where the peak production is $600 \mathrm{MT} / \mathrm{yr}$ and a non-chemical lunar 
quenchgun delivers LLOX to lunar orbit. The Earth LOX demand reaches a maximum value during the years of launcher delivery then decreases dramatically to near the pre-delivery values. As LLOX production increases over the years 2013 to 2017, the two paths diverge until there is no Earth LOX required to support the transport of goods to the Moon in 2018. The burdensome LOX umbilical cord to the Earth is completely severed. Of the three impact studies examined, only the high LLOX production case had sufficient LLOX to drive the Earth LOX to zero during peak production.

This LOX independence from Earth translates directly into a decrease in mass that must be delivered to Low Earth Orbit (LEO), as shown in Figure 13. The mass to be delivered to LEO in the high production case is lower for some of the years after the launcher is delivered, even though more equipment is required at the lunar surface. Two exceptions to this are the years 2014 and 2016, where the extra LLOX equipment and additional fuel for lunar orbit operations necessitate another transfer vehicle flight. The system finally settles to optimal performance in 2018, and the mass delivered to LEO is nearly $30 \%$ lower for the high production case than in the LECS. By similar analysis of the other two cases, it is clear that a quenchgun is unadvisable unless LLOX production is aggressively pursued.

For this scenario, the inclusion of a lunar quenchgun would require two years of heavy investment for launcher delivery. This is followed by five years of high overhead and non-optimal operations as the LLOX production is being increased. Seven years after the initial investment, the system first breaks even in terms of mass delivered to LEO. A shorter LLOX production build up time could speed the return on the initial investment. The benefits obtained in 2018 could continue for another 10 years in the best case scenario. 
This corresponds to approximately 10,000 launch cycles, the useful life of the launcher before failure or comprehensive maintenance. Taking all of these factors into account, the addition of a superconducting quenchgun to this scenario is considered nominal at best. 
Figure 8: LOX From Earth (MT)

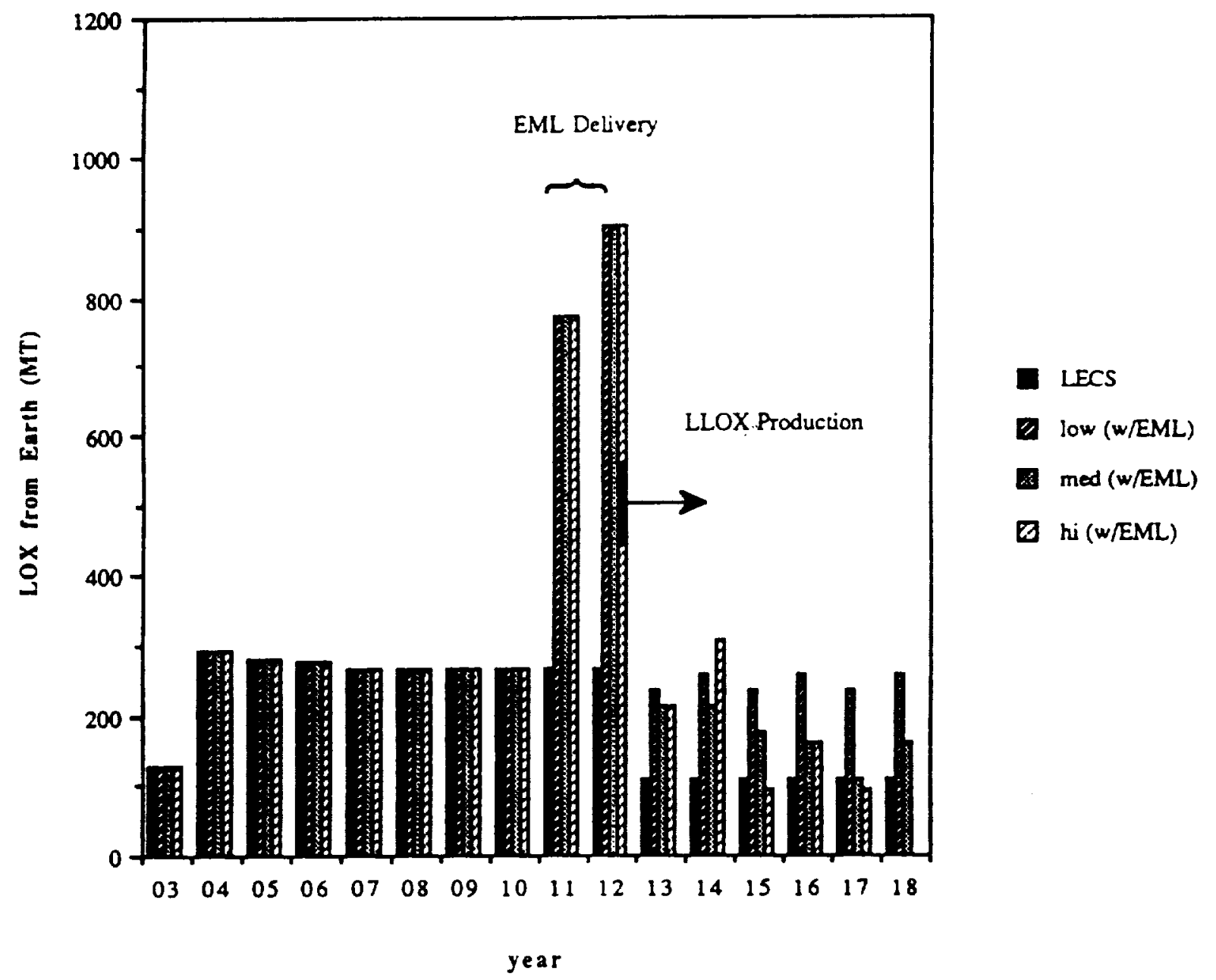


Figure 9: Lunar Surface-to-Orbit Flights

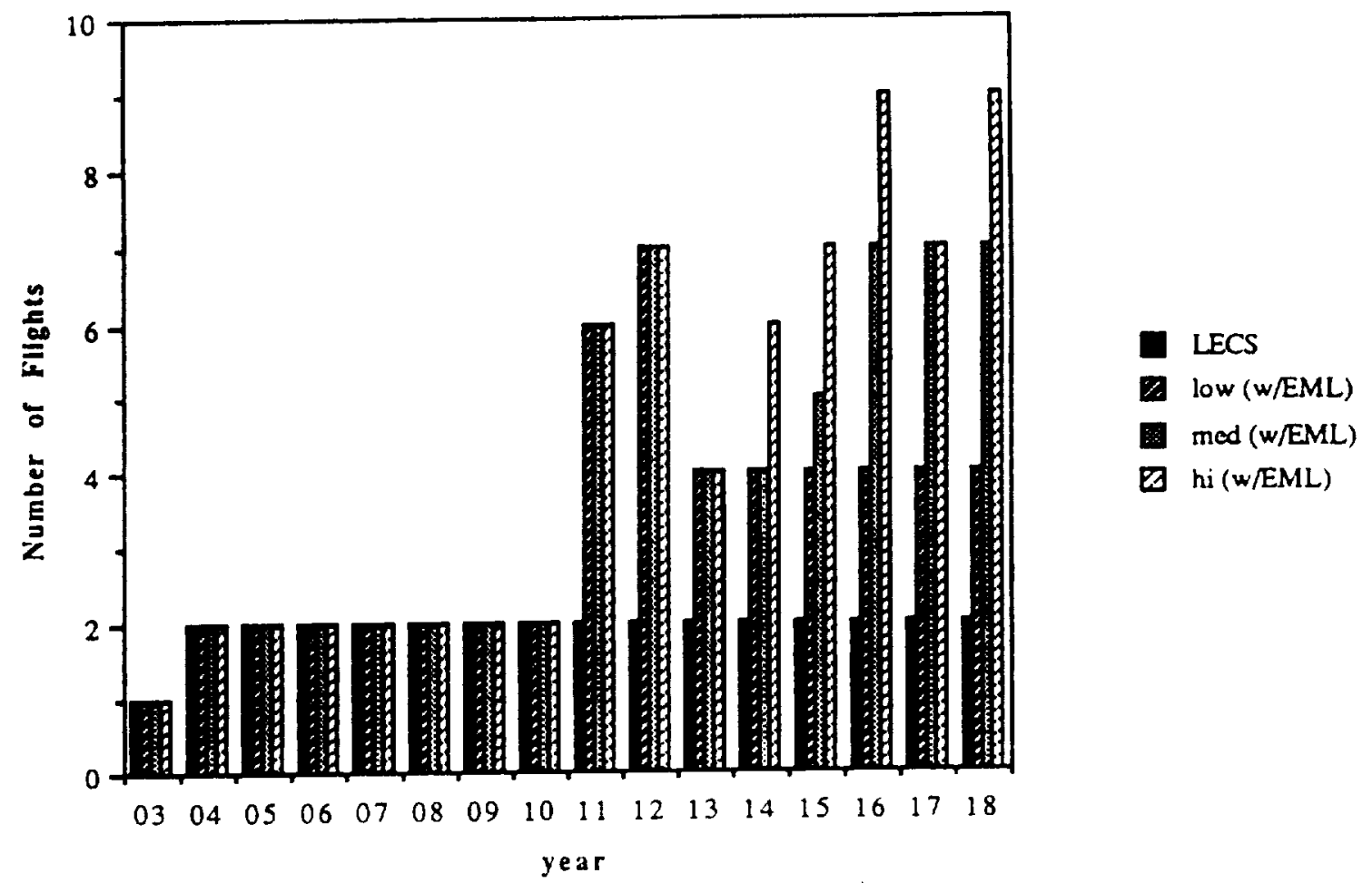

Figure 10: Orbit-to-Orbit Flights

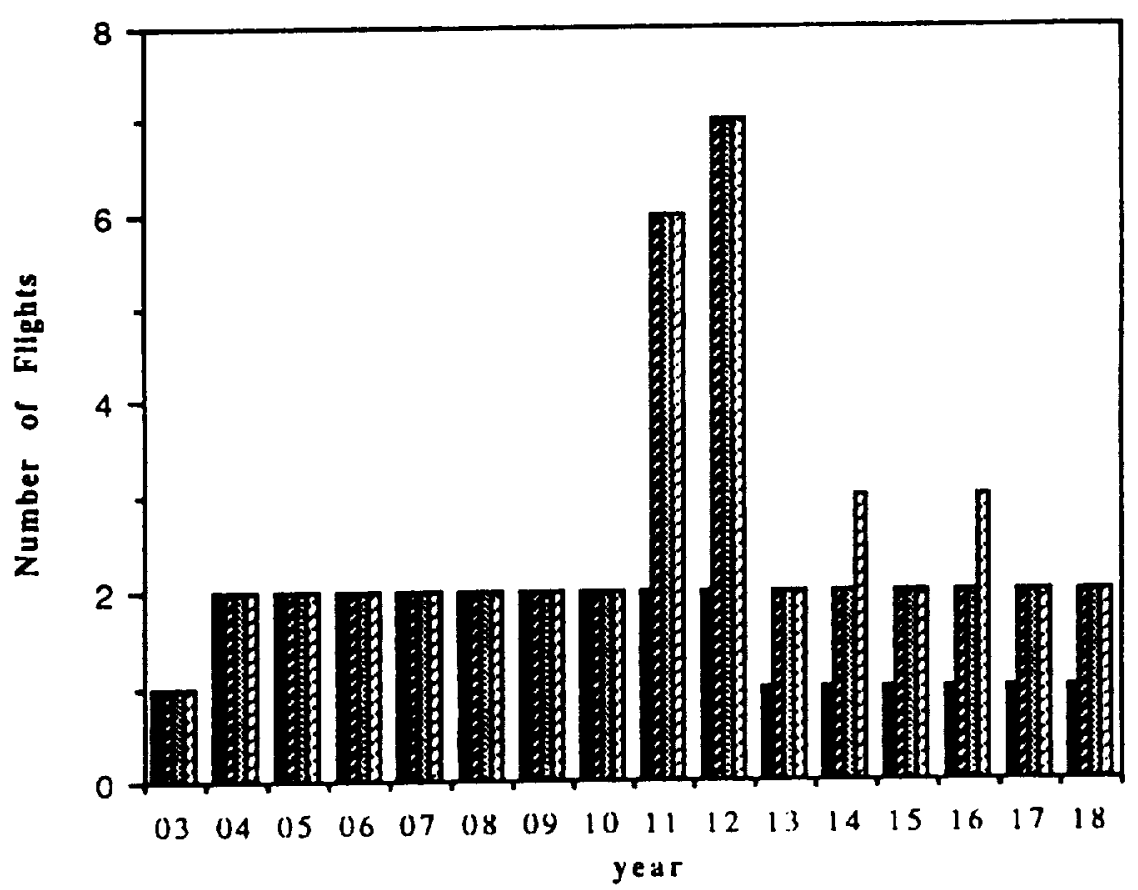

$\square$ LECS

7 low (w/EML)

med (w/EML)

E hi (w/EML) 
Figure 11: LECS Earth LOX Requirement

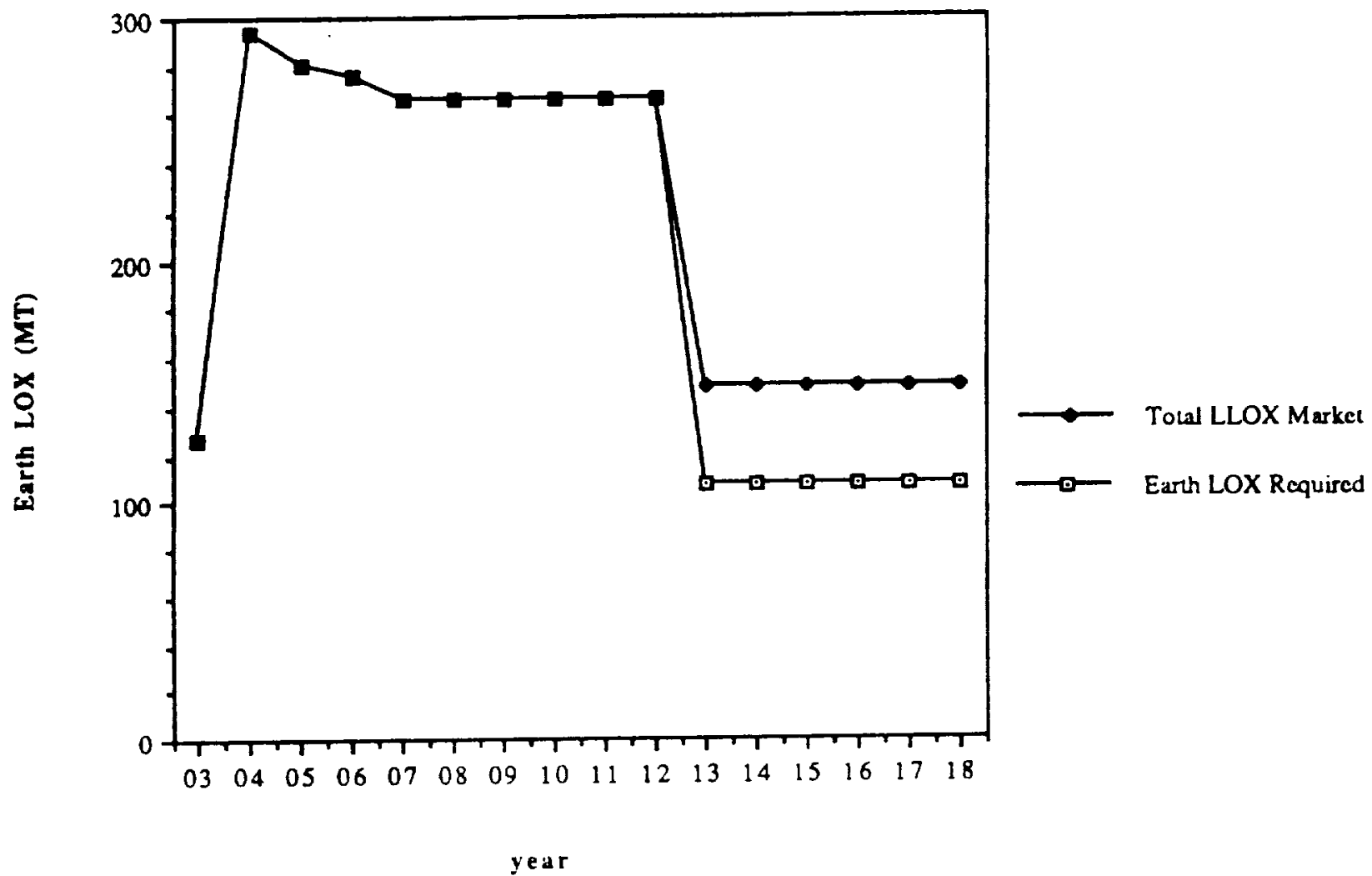

Figure 12: Earth LOX Required for High LLOX Case

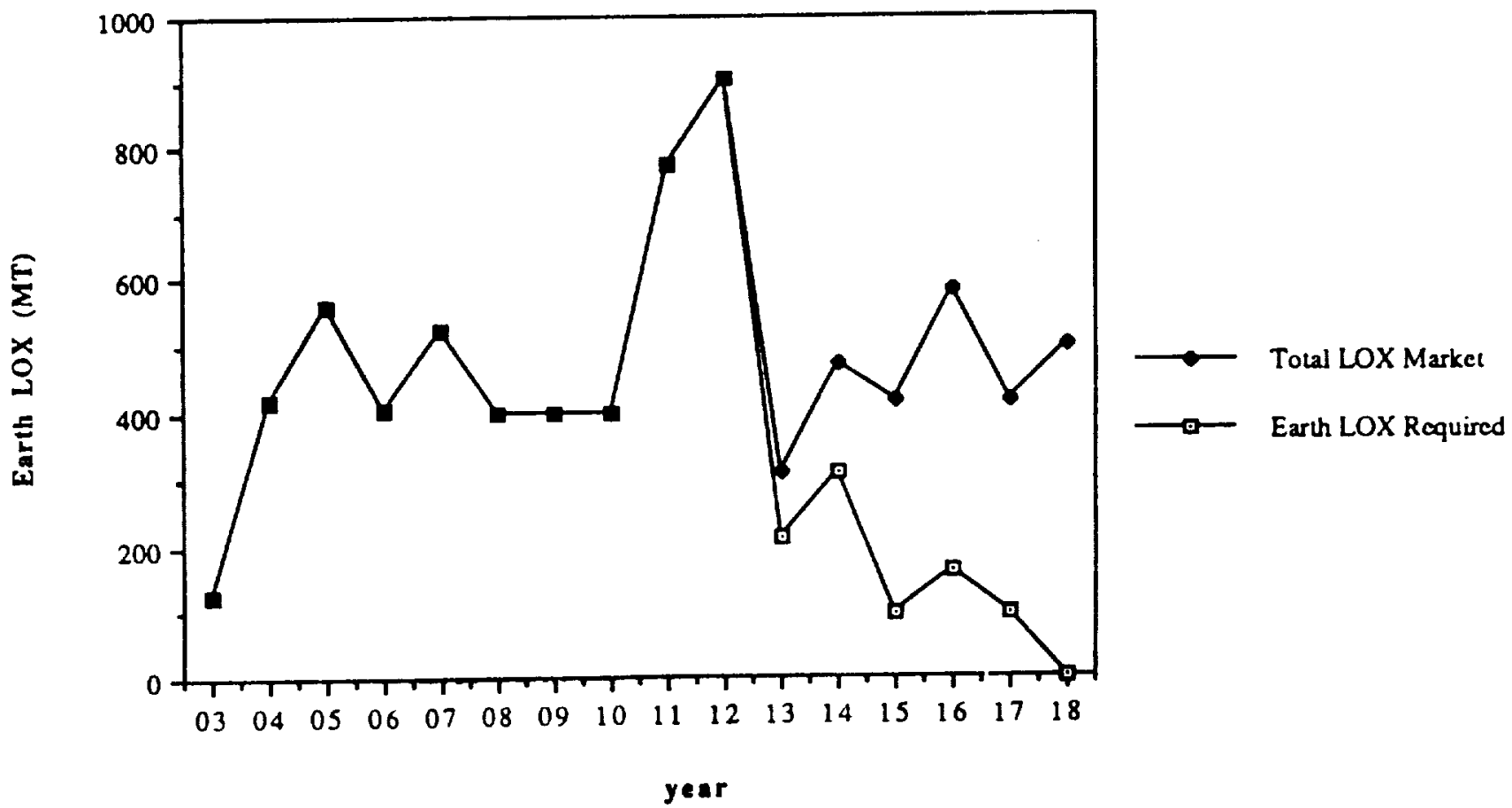


Figure 13: Mass to LEO (MT)

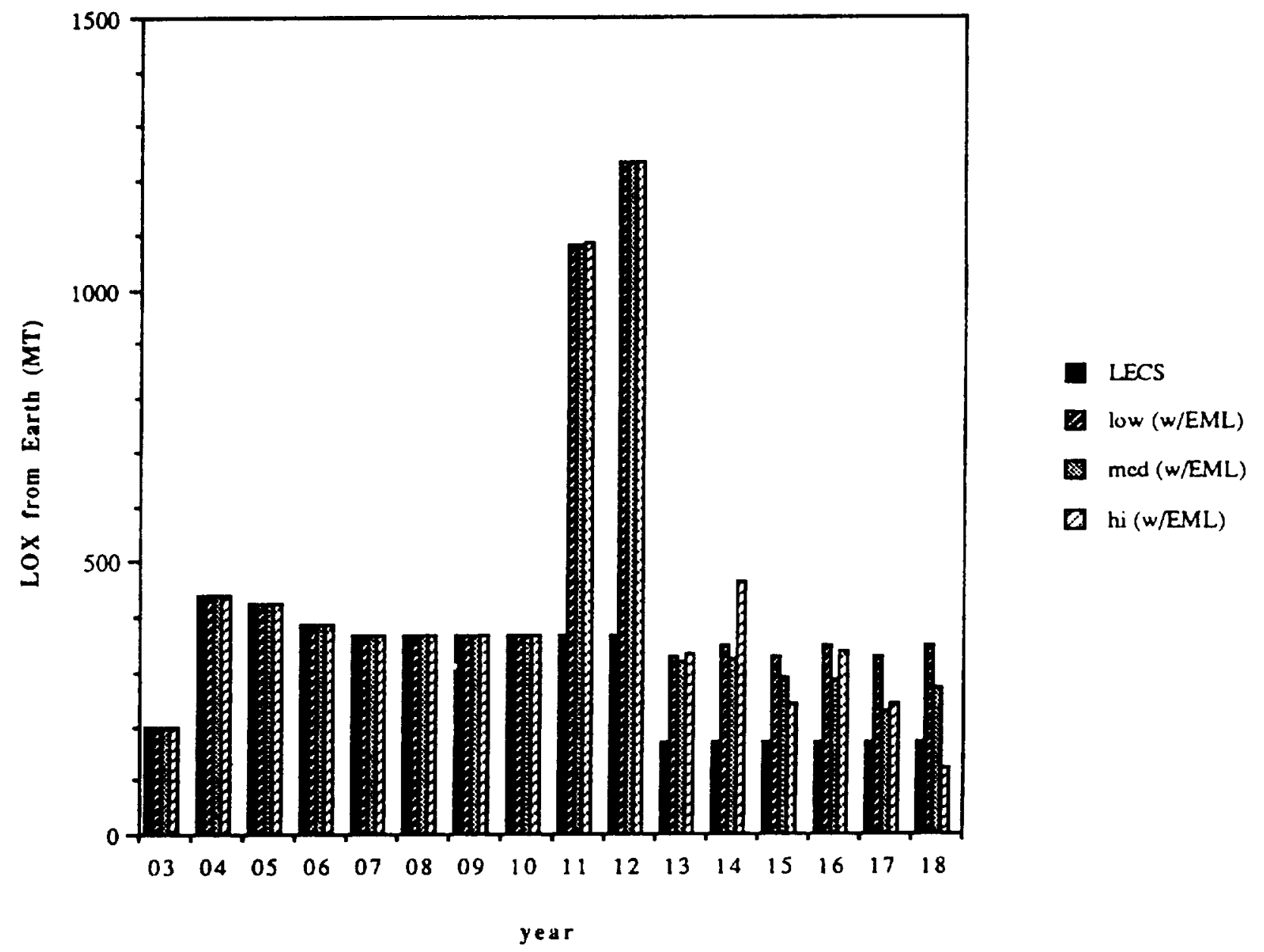




\section{REFERENCES}

1. Pioneering the Space Frontier; The Report of the National Commission on Space, Bantam Books, New York, May 1986.

2. Duke, M., Mendell, W., and Roberts, B., "Strategies for a Permanent Lunar Base," Lunar Bases and Space Activities of the 21st Century, Lunar Planetary Institute, Houston, Texas, 1985.

3. Davis, H.P., "Lunar Oxygen Impact Upon STS Effectiveness," Report No. EEI-8363, Eagle Engineering, Inc., Houston, Texas, May 1983.

4. O'Neill, G.K., "The Low (Profile) Road to Space Manufacturing," Astronautics and Aeronautics, Volume 16, Number 3, March 1978, pages 18-32.

5. Snow, W.R., Kubby, J.A., and Dunbar, R.S., "A Small Scale Lunar Launcher for Early Lunar Material Utilization," Space Manufacturing Four, Proceedings of the 5th Princeton/AIAA Conference, March 18-21, 1981.

6. Kolm, K., Snow, W., Mongeau, P., and Willig, R., "Preliminary Design of a Superconducting Quenchgun for Launching One Ton Payloads from the Lunar Surface," prepared for Large Scale Programs Institute by EML Research Inc., May 1988.

7. Snow, W., Willig, R., "Scaling Laws for a Superconducting Quenchgun for Launching One to Ten Ton Payloads of Liquid Oxygen from the Lunar Surface," prepared for LSPI by EML Research, Inc., May 1989.

8. Arnold, W., et al. "Mass Driver II Engineering," Space Resources and Space Settlements, NASA SP-428, 1979, pp 119-151.

9. Bilby, C., et al., "A Lunar Electromagnetic Launcher", Symposium on Lunar Bases and Space Activities in the 21st Century, Paper No. LBS-88-073, April 1988 


\section{APPENDIX I: SOURCE CODE}

PROGRAM EMLMOD

IMPLICIT DOUBLE PRECISION $(A-H, L-Z)$

OPEN (UNIT $=2$, FILE=' SUP PORT. DAT')

OPEN (UNIT $=3, F I L E='$ EML . OUT')

OPEN (UNIT $=4$, , FILE $=$ ' SUP PORT . OUT')

CALL EMLSI ZE (BARM, CHARGR, LLOXM, CHARGT, BARBOR, BARLEN, ARMM, MINJ , +PCM, SUPPM, P INJ, PCP , CCM, CCPOW, TRUCKM, EMLTOT, EMLRM)

CALL SUPPORT (BARM, CHARGP, TOTALM, TOTALRM, REFTEM, RADM, REFM, REFRM, +GENM, RECA, CONVM, NUNITS, DISTM, GENRM, CONVRM, IG, IC, PRADA, PRADM, POWRM, +POWM, NEWPOW, TRUCKM, EMLTOT, EMLRM)

END

c-

SUBROUTINE EMLSIZE (BARM, CHARGP, LLOXM, CHARGT, BARBOR, BARLEN, ARMM,

+MINJ , PCM, SUPPM, PINJ , PCP , CCM, CCPOW, TRUCKM, EMLTOT, EMLRM)

IMPLICIT DOUBLE PRECISION (A-H,L-Z)

C.... PROGRAM TO SIZE EMI REQUIRED FOR LLOX PAYLOAD AND LAUNCH RATE

C..... RELATIONS COME FROM CURVES FIT TO EML RESEARCH INC. CASE

C STUDY RESULTS IN APPENDIX - MINJ, PCM, SUPPM ARE EROM 5/88 PAPER

C..... INPUTS: LLOXM, TCHARGE

C.... . OUTPUTS: BARBOR, BARLEN, BARM, ARMM, ELAUNCH, PLAUNCH

C.....VVARIABLES :

C LLOXM $=$ LLOX MASS (mt)

C CHARGT $=$ TIME BETWEEN LAUNCHES, CHARGING TIME (hr)

C BARBOR=BARREL BORE (m)

C BARLEN=BARREL LENGTH (m)

C BARM=BARREL MASS (mt)

C ARMM=ARMATURE MASS (mt)

C MINJ $=$ INJECTOR MASS $=3 *($ LLOXM)

C PCM=POWER CONTROLLER MASS $=(.5 / 150) *$ BARLEN

C PCP=POWER CONTROLIER POWER-NOMINAL CONSUMPTION OF $5 \mathrm{k} N$

C PINJ=INJECTOR POWER-SCALES IINEARLY - $5 \mathrm{~kW} / T O N$ LLOX

C CCM=CONTROL CENTER/STORAGE AREA MASS-MODELED AS BASE HAB-11.7mt

C CCPOW=CONTROL CENTER POWER - $75 \mathrm{~kW}$ - LBM HAB POWER

C SUPPM=SUPPORT STRUCTURE MASS $=(25 / 150) \star B A R M$

C ELAUNCH=LAUNCH ENERGY (GJ)

C CHARGP=POWER REQUIRED OVER CHARGING PERIOD (W)

C....USER INPUTS

WRITE $(6, \star)$ 'ENTER THE LLOX PAYLOAD MASS (IN METRIC TONS)'

$\operatorname{READ}(5, *)$ LLOXM

WRITE $\left(6,{ }^{*}\right)$ 'ENTER THE TIME INTERVAL BETWEEN LAUNCHES (IN HR)'

$\operatorname{READ}(5, *)$ CHARGT

C. . . . USER INPUT COMPLETE

BARBOR $=.69137 \mathrm{DO}+.27902 \mathrm{DO} \star \mathrm{LLOXM}-4.6170 \mathrm{D}-2 \star \mathrm{LLOXM} \star \star 2+4.3868 \mathrm{D}-3 *$

+ LLOXM**3-1.61 64D $-4 *$ LLOXM**4

$\mathrm{BARM}=664.42 \mathrm{DO}-1871.9 \mathrm{DO}$ * $3 \mathrm{ARBOR}+1943.1 \mathrm{DO}$ *BARBOR * $2-893.74 \mathrm{DO}$ *BARBOR

$+\star \star 3+448.09 \mathrm{DO} * \mathrm{BARBOR} \star \star 4$

BARLEN $=17.774 \mathrm{DO}-30.493 \mathrm{DO} * \mathrm{BARBOR}+185.0 \mathrm{D} 0 * \mathrm{BARBOR} \star 2$

$A R M M=-4.332 D 0+14.955 D 0 * B A R B O R-18.957 D 0 * B A R B O R * \star 2+10.439 D 0 * B A R B O R$

$+\star \star 3-1.7452 \mathrm{DO} \star \mathrm{BARBOR} \star \star 4$

ELAUNCH $=-4.7921 \mathrm{D} 0+19.624 \mathrm{DO}$ *BARBOR-28.317D0*BARBOR * $2+17.238 D 0 *$

$+B A R B O R \star \star 3-1.2535 D 0 \star B A R B O R \star \star 4$

$A C C E L=3921.4 D 0-4128.8 D 0 * B A R B O R+1195.9 D 0 * B A R B O R \star * 2$

CHARGP $=($ ELAUNCH $* 1.0 D 9) /($ CHARGT $* 3.600 D 3)$

MINJ $=3.0 D O *$ LLOXM

PINJ $=5.0 D 0 *$ LIOXM

$P C M=(0.5 D 0 / 150.0 D 0) \star B A R L E N$

$\mathrm{PCP}=5.0 \mathrm{DO}$

SUPPM $=(25.0 D 0 / 150.0 D 0) \star B A R L E N$

$\mathrm{CCM}=1.17 \mathrm{D} 1$

CCPOW $=7.5 D 3$

TRUCKM $=1.900$

WRITE $(3,5)$ ' LLOX PAYLOAD, IN TONS $=$ ', LLOXM

WRITE $(3,5)$ ' HOURS BETWEEN LAUNCHES $='$, CHARGT

WRITE $(3,10)^{\prime}$,

WRITE $(3,5)$ 'BARREL BORE, IN $M=$ ', BARBOR

WRITE $(3,10)^{\prime}$ BARREL MASS, IN TONS $=$ ', BARM

WRITE $(3,10)$ ' BARREL LENG $=$, IN $M=$ ', BARLEN 
WRITE $(3,5)$ 'BARREL SUPPORT STRUCTURE MASS, IN TONS $=$ ',SUPPM

WRITE $(3,15)$ 'ARMATURE MASS, IN TONS $='$, ARMM

WRITE $(3,10)$ ' PROJECTILE ACCELERATION, IN gee' 's = ', ACCEL

WRITE $(3,10)$,'

WRITE $(3,5)$ 'PAYLOAD INJECTOR MASS, IN TONS = 'MINJ

WRITE $(3,5)$ 'PAYLOAD INJECTOR POWER, IN $\mathrm{kW}=$, PINJ

WRITE $(3,10)^{\prime}$ ',

WRITE $(3,5)$ ' POWER CONTROLLER MASS, IN TONS $=$, PCM

WRITE $(3,5)$ 'POWER CONTROLLER POWER, IN $k$ 'N $=$ ', PCP

WRITE $(3,10)^{\prime}$ ',

WRITE $(3,5)$ ' CONTROL CENTER MASS, IN TONS $=\prime, \mathrm{CCM}$

WRITE $(3,5)$, CONTROL CENTER POWER, IN $\mathrm{kW}=\prime,(\mathrm{CCPOW} / 1.0 \mathrm{D} 3)$

WRITE $(3,10)^{\prime}$,

$E M L T O T=B A R M+A R M M+M I N J+P C M+S U P F M+C C M$

$E M L R M=(S U P P M+B A R M) / 20.0 D O+A R M M / 5.0 D O+(M I N J+P C M+C C M) / 10.0 D 0$

WRITE $(3,10)$ 'TOTAL EML EMPLACEMENT MASS, IN TONS = "EMLTOT

WRITE $(3,10)$ ' ANNUAL RESUPELY MASS FOR LAUNCHER, IN TONS = , EMLRW

5

10 EORMAT (A, E8.3)

15 EORMAT $(A, E 7.5)$

RETURN

END

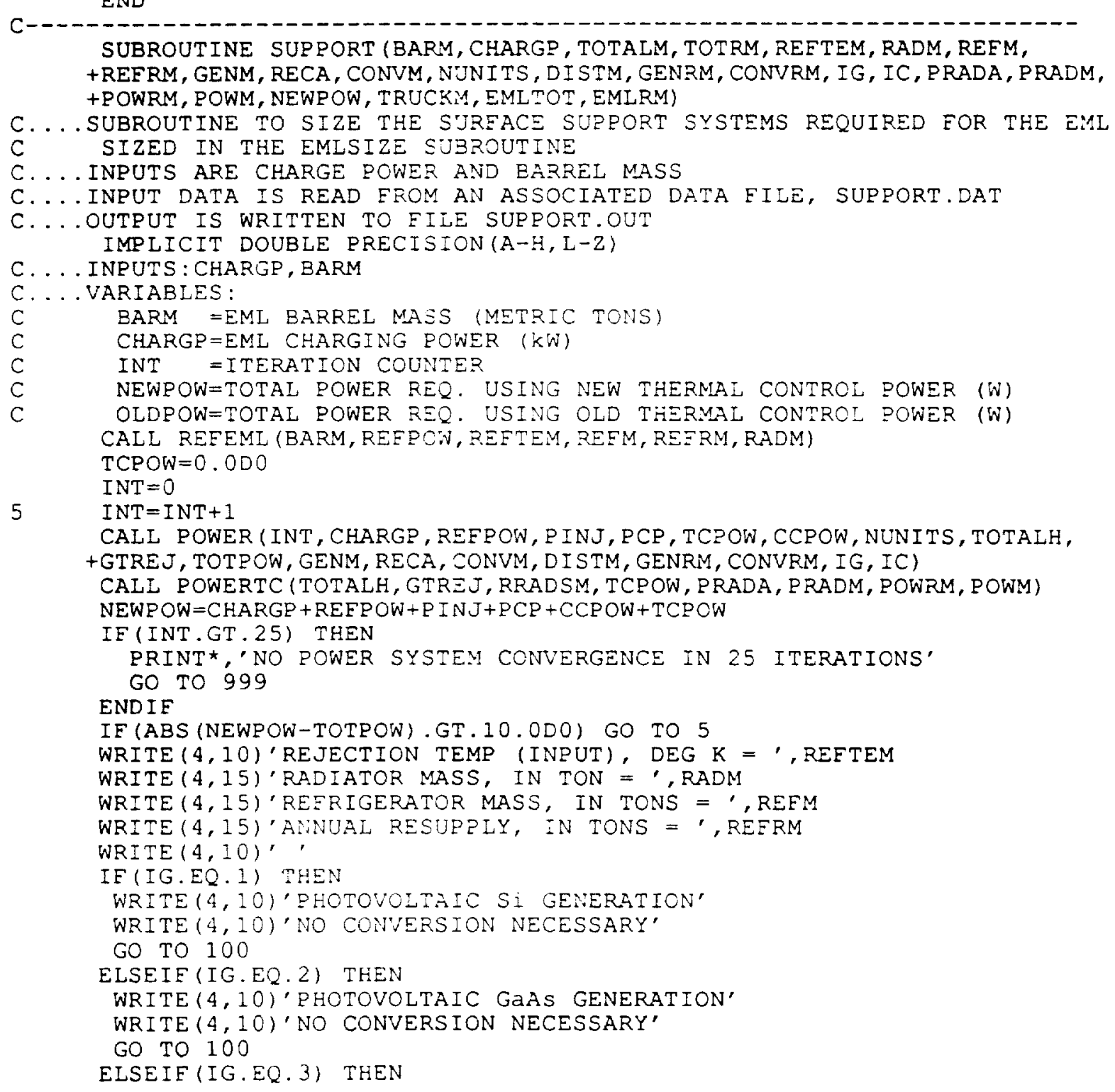




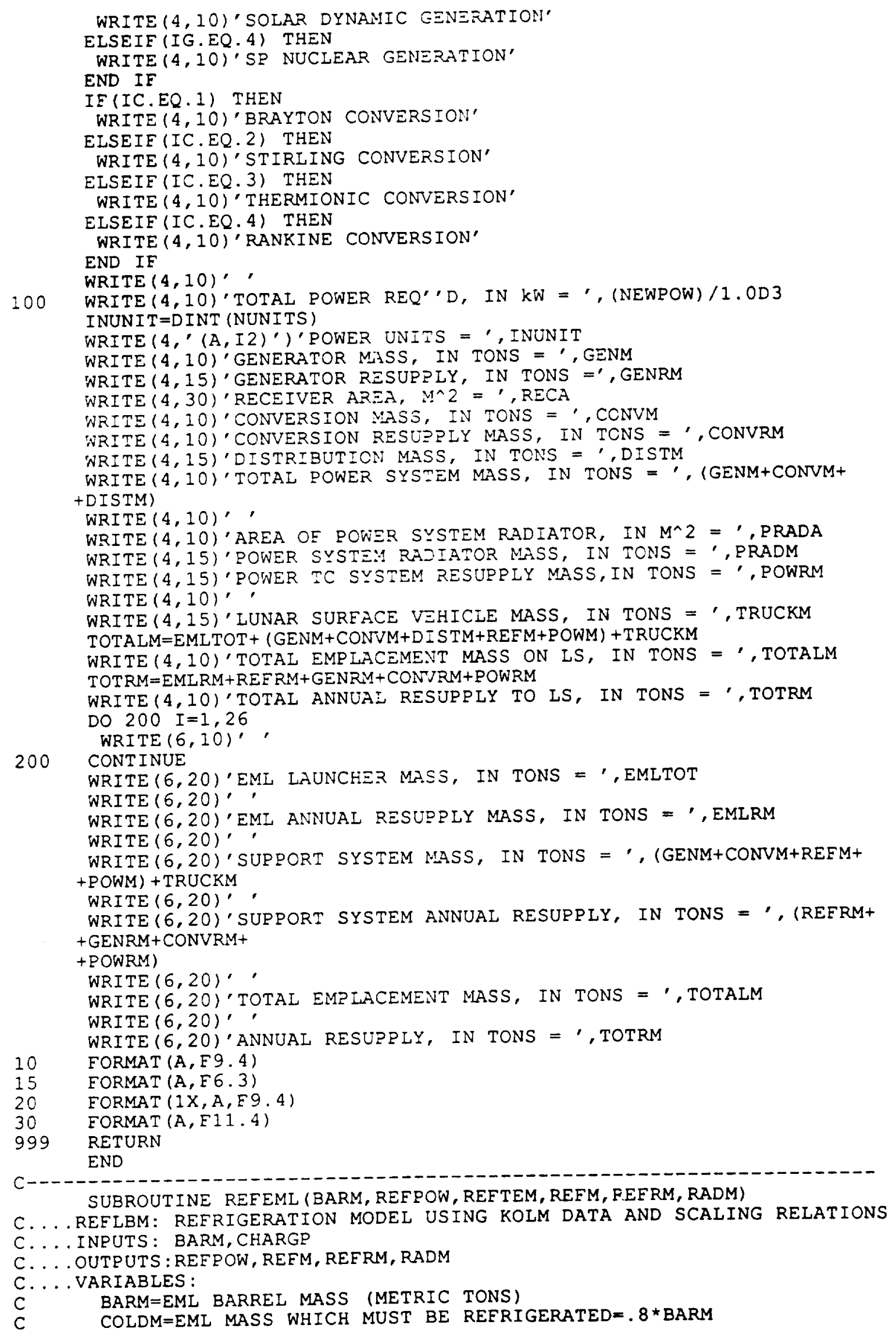




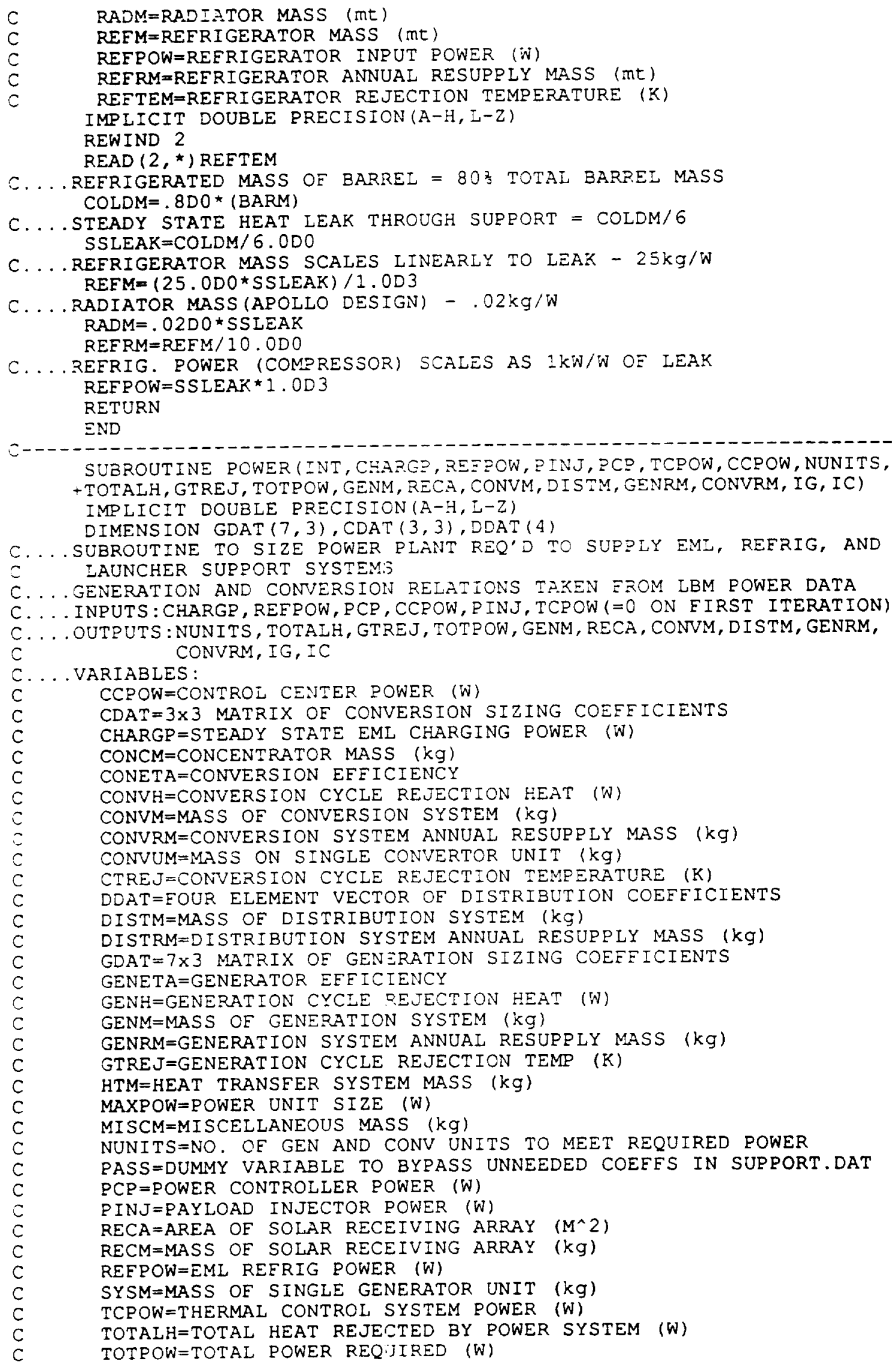




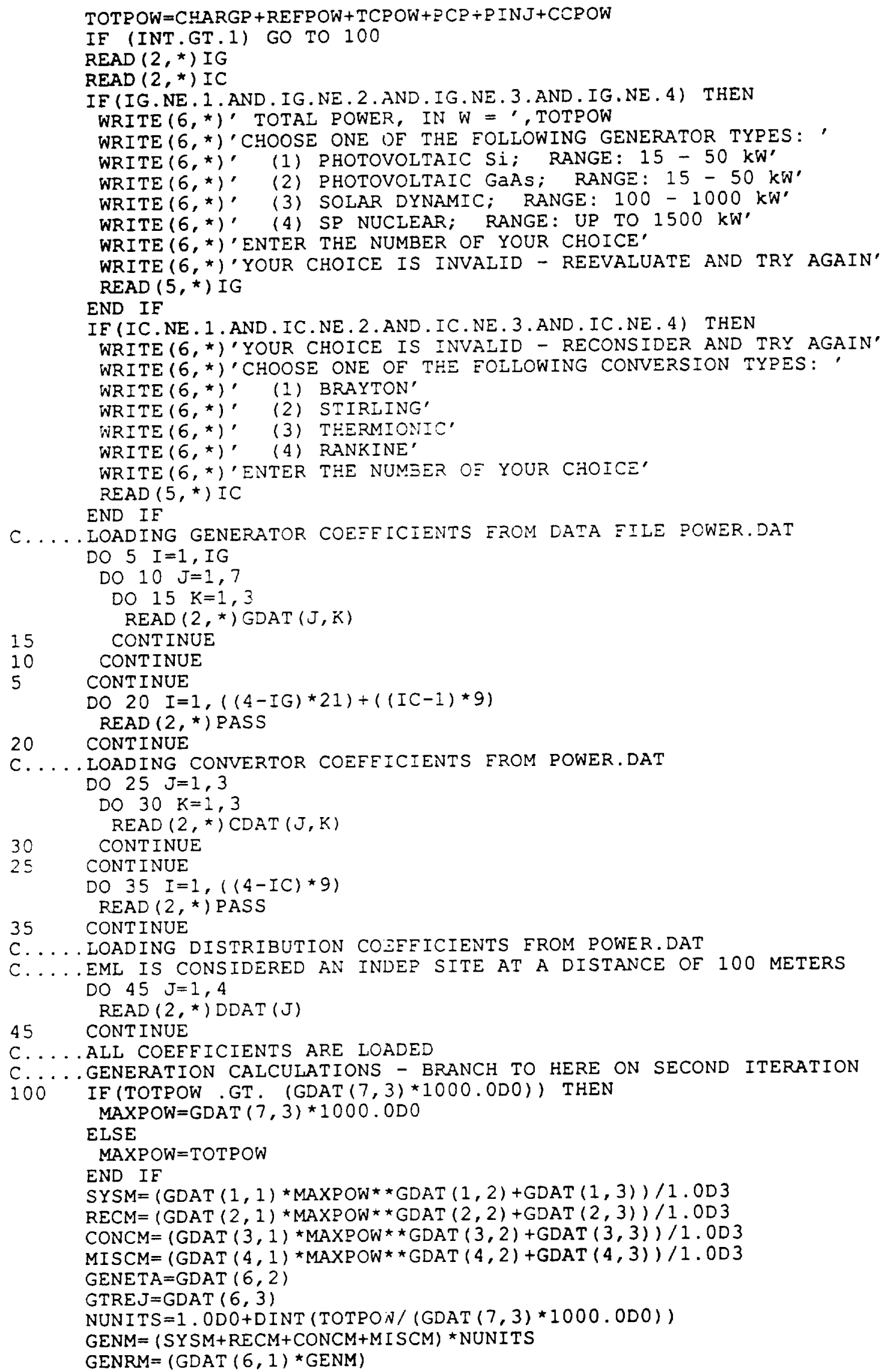




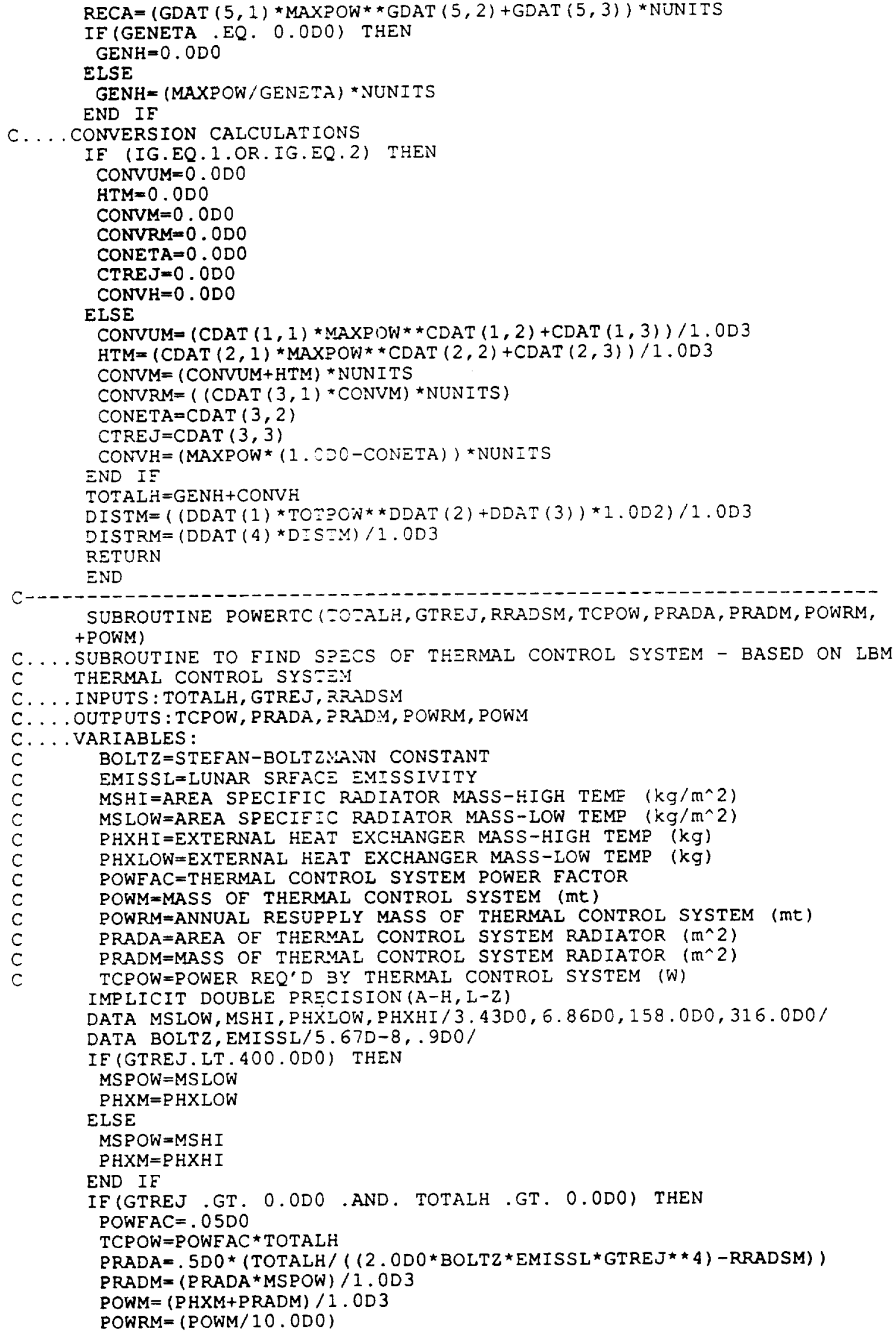


ELSE

TCPOW $=0.0 D 0$

PRADA $=0.0 D 0$

$P R A D M=0$. ODO

POWM $=0.0 D 0$

POWRM $=0$. ODO

END IF

RETURN

END 


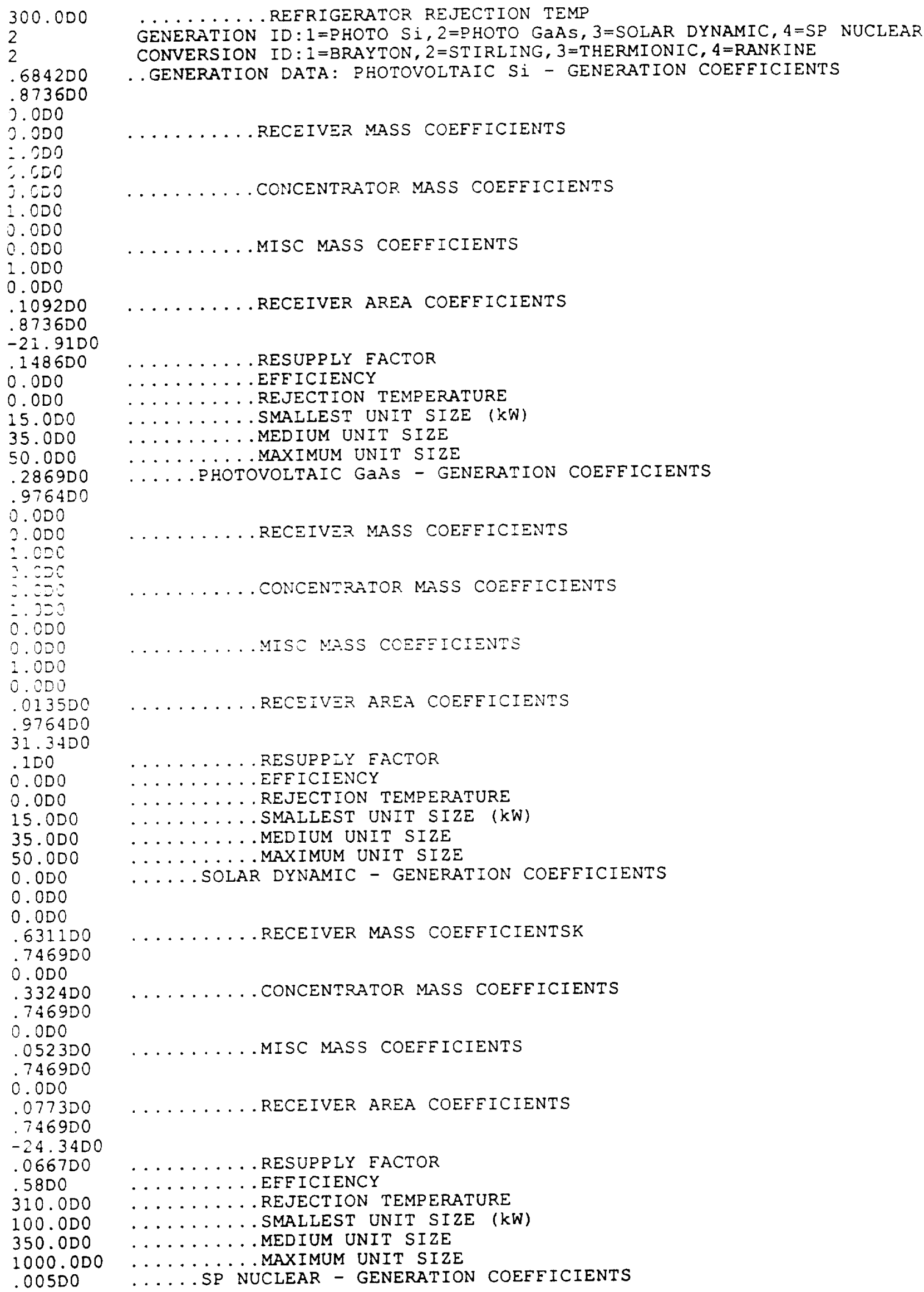




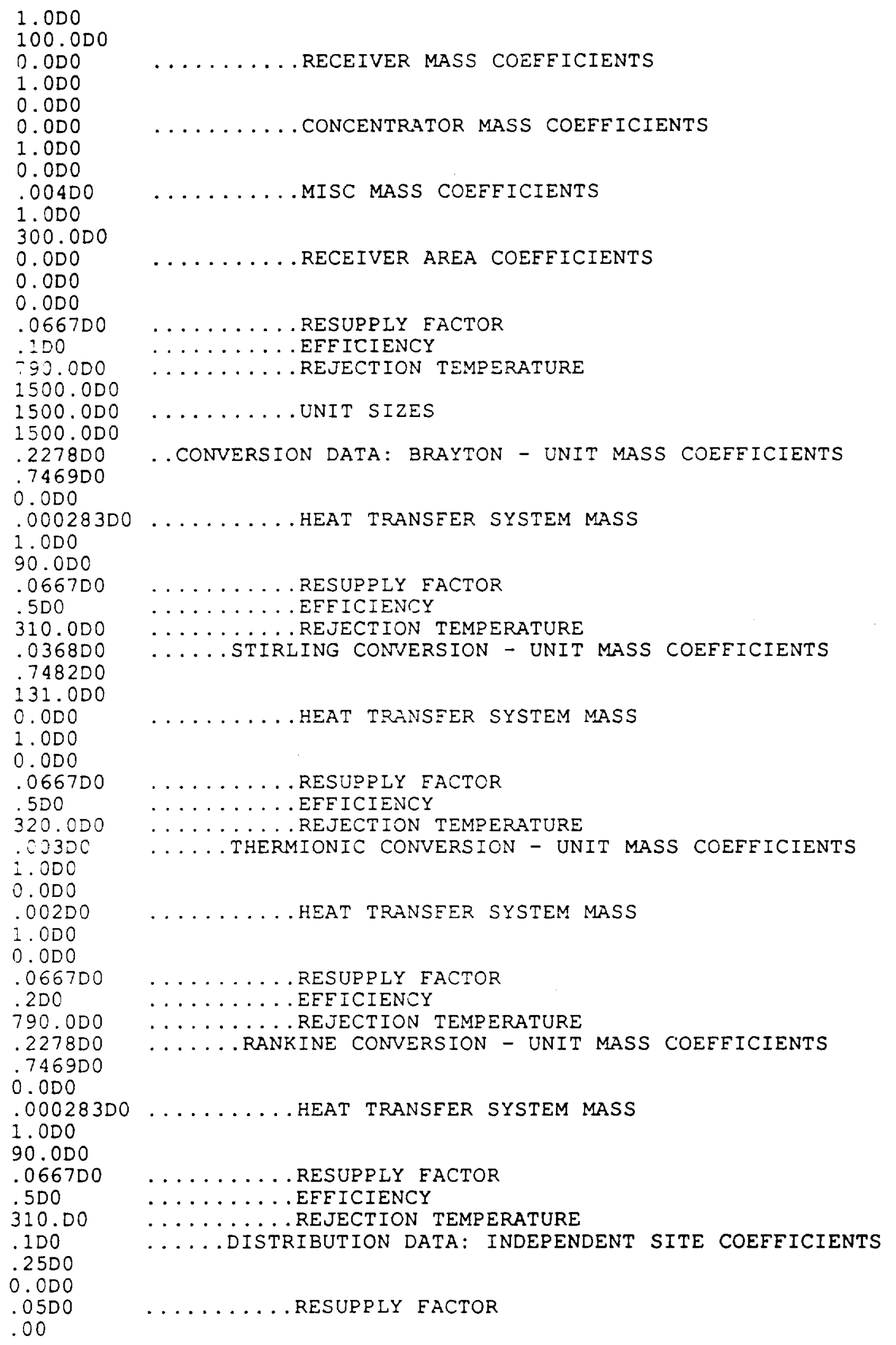




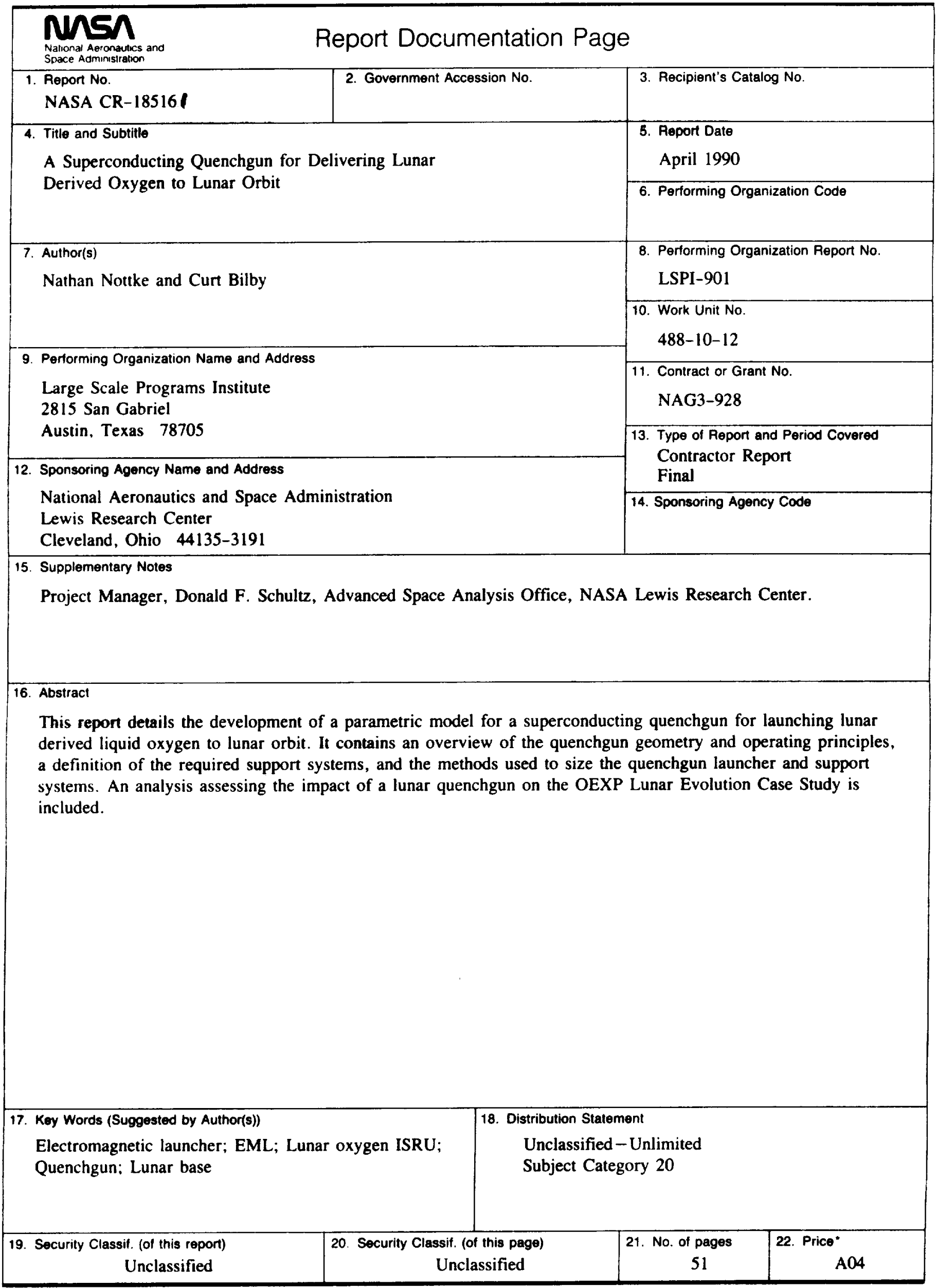



National Aeronautics and

Space Administration

Lewis Research Center

Cleveland. Ohio 44135

Oncial Bustiness

Ponaly for Pitvats Uas $\$ 500$
FOURTH CLASS MAIL.

ADDRESS CORRECTION REQUESTED

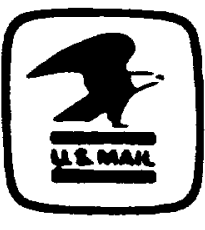

Postage and Foes Paid National Aeronautics and

Spece Administration NASA-451 